\title{
Finite-Time Stabilization of Memristive Cohen-Grossberg Neural Networks with Time-Varying Delay
}

\author{
Ge Li (D), Yaqiong Li $(\mathbb{D}$, and Zhaohui Yuan \\ College of Mathematics and Econometrics, Hunan University, Changsha 410082, Hunan, China \\ Correspondence should be addressed to Yaqiong Li; yqli@hnu.edu.cn
}

Received 3 February 2018; Revised 21 August 2018; Accepted 13 September 2018; Published 26 November 2018

Academic Editor: Thierry Floquet

Copyright () $2018 \mathrm{Ge} \mathrm{Li} \mathrm{et} \mathrm{al.} \mathrm{This} \mathrm{is} \mathrm{an} \mathrm{open} \mathrm{access} \mathrm{article} \mathrm{distributed} \mathrm{under} \mathrm{the} \mathrm{Creative} \mathrm{Commons} \mathrm{Attribution} \mathrm{License,} \mathrm{which}$ permits unrestricted use, distribution, and reproduction in any medium, provided the original work is properly cited.

\begin{abstract}
In this paper, the finite-time stabilization problem for memristive Cohen-Grossberg neural networks with time-varying delay is discussed. By using the novel fixed point theory of set-valued maps, we establish the existence theorem of equilibrium point. In order to realize the finite-time stabilization, two different kinds of discontinuous state feedback controllers whether including time-varying delay are designed. Based on the extended Filippov framework and two different kinds of methods whether using finite-time stability theory, some novel sufficient conditions and the upper bound of the settling time for finite-time stabilization are proposed. Finally, two numerical examples are given to demonstrate the validity of theoretical results.
\end{abstract}

\section{Introduction}

Memristor, first hypothesized by Chua in 1971 [1], was realized by Hewlett-Packard (HP) lab in 2008 [2]. The new circuit possesses memory characteristic as biological neurons, which is distinct from other circuit elements such as resistor and capacitor. As a result, memristor is widely used in artificial neural networks for emulating human brain [3]. When using memristor to replace other resistors, researchers can construct a new kind of neural networks named memristor-based neural networks (MNNs). Nowadays, MNNs are widely used in the area of science and technology, such as artificial intelligence, signal processing, and associate memory [3-6].

Due to the state-dependent switching feature, MNNs can be viewed as a differential equation with discontinuous righthand side. Thus, the differential inclusion theory is a new kind of effective methods to study the dynamical behaviors of various MNNs. There are already many theoretical results about MNNs, such as stability and synchronization [7-12]. In [8], the authors proposed a new kind of complex-valued memristor-based neural networks with time-varying delays and studied their exponential stability by using some analytic techniques and constructing a Lyapunov functional. However, due to the switching feature of memristor, the dynamical behaviors of MNNs are always unstable such as oscillation and chaos. Thereby, it is necessary and challengeable to investigate the stabilization problem of unstable MNNs by designing suitable controllers.

In most researches about the stabilization of MNNs, the converge time of system states is sufficiently large such as exponential stabilization and asymptotic stabilization. However, researchers always hope the converge time can be shortened in practice. It is worth noting that the finite-time stability theorem is a very effective method to realize this goal. The finite-time stabilization (FTS) indicates the system states can keep in a certain range of equilibrium point after a finite time. Besides the faster converge speed, FTS also has other desirable advantages when compared with the infinite-time stabilization, such as better robustness and disturbance rejection properties $[13,14]$. In recent years, the finite-time synchronization and FTS of discontinuous neural networks have received great attention [15-19]. In [16], the finite-time synchronization of time-varying delayed neural networks (DNNs) with discontinuous activations was studied by using the famous finite-time stability theorem. In [17], the authors studied the finite-time projective synchronization issue of memristor-based delay fractional-order neural networks by using the definition of finite-time projective synchronization. On the other hand, the discontinuous 
controllers were creatively designed to realize the FTS of neural networks with discontinuous right-hand side [18, 19]. However, there are a few papers concerning the finite-time stabilization of MNNs [20-23]. In [20], the authors investigated the FTS of MNNs by designing the discontinuous state feedback controller, but they ignored time delay. In fact, time delay is always inevitable in most neural networks due to the finite transmitting speed between neuron signals. In [23], the authors mainly studied the finite-time stability and synchronization problems of memristor-based fractional-order fuzzy cellular neural network with time delay. For realizing the FTS of discontinuous neural networks, it is worth noting that discontinuous controllers are always more effective than conventional continuous controllers. This is mainly because the uncertain differences of Filippov solutions can be well handled by using discontinuous controllers. On the other hand, Cohen-Grossberg neural networks that was introduced by Cohen and Grossberg in 1983 is also an important kind of neural networks [24]. There always exist many results about the dynamical behaviors of Cohen-Grossberg neural networks [25-28]. In [26], the global and local finite-time synchronization for a class of memristor-based CohenGrossberg neural networks with time-varying delays are discussed. In [28], the authors studied the finite-time stability and synchronization problem of a class of memristor-based fractional-order Cohen-Grossberg neural network with time delay by using differential inclusion theory and Gronwalls inequality. However, the time delay is constant and the activation functions are bounded in [28]. To the best of our knowledge, there are few papers concerning the FTS of memristive Cohen-Grossberg neural networks with timevarying delay.

The main contributions of this paper have three aspects. First, the existence of equilibrium point is studied by using the novel fixed point theory of set-valued maps. Second, there are few results about the finite-time stabilization of neural networks concerning the factor of memristor, amplification function, and time-varying delay. Third, two discontinuous controllers whether including time-varying delay and two analysis methods whether using finite-time stability theory are considered.

The structure of this paper is organized as follows. In Section 2, the delayed memristive Cohen-Grossberg neural networks and some preliminary knowledge are presented. In Section 3, the existence theorem of equilibrium point is obtained. In Section 4, main theorems and some sufficient conditions about finite-time stabilization are provided. In Section 5, we illustrate the effectiveness of theoretical results by using numerical examples. Finally, conclusions and future research topics are presented in Section 6.

Notations. $\mathbb{R}$ and $\mathbb{R}^{n}$ denote the space of real number and the n-dimensional Euclidean space, respectively. Let $X \subseteq \mathbb{R}^{n}$, $P_{k c}(X)$ denotes the collection of all nonempty, compact, and convex subset of $X$. For any column vector $x=$ $\left(x_{1}, x_{2}, \ldots, x_{n}\right)^{T} \in \mathbb{R}^{n}$, the norm of $x$ is defined as $\|x\|_{1}=$ $\sum_{i=1}^{n}\left|x_{i}\right|$. Given vectors $x=\left(x_{1}, x_{2}, \ldots, x_{n}\right)^{T}$ and $\mathrm{y}=$ $\left(\mathrm{y}_{1}, \mathrm{y}_{2}, \ldots, \mathrm{y}_{n}\right)^{T} \in \mathbb{R}^{n},\langle x, \mathrm{y}\rangle=x^{\mathrm{T}} \mathrm{y}=\sum_{i=1}^{n} x_{i} \mathrm{y}_{i}$ denotes the inner product of $x$ and $y$, and the superscript $T$ represents the transposition of a vector or matrix. Finally, sign $(\cdot)$ stands for the sign function.

\section{System Description and Preliminaries}

In this section, the memristive Cohen-Grossberg neural networks with time-varying delay and some important preliminaries are introduced. The neural network system considered in this paper is described as follows [26]:

$$
\begin{aligned}
\dot{v}_{i}(t)= & -a_{i}\left(v_{i}(t)\right)\left[b_{i}\left(v_{i}(t)\right)-\sum_{j=1}^{n} c_{i j}\left(v_{i}(t)\right) f_{j}\left(v_{j}(t)\right)\right. \\
& \left.-\sum_{j=1}^{n} w_{i j}\left(v_{i}(t)\right) g_{j}\left(v_{j}(t-\tau(t))\right)-I_{i}\right], \quad i \in \mathbb{N},
\end{aligned}
$$

where $\mathbb{N}=\{1,2, \ldots, n\} ; \quad v_{i}(t)$ represents the voltage of capacitor $\mathrm{C}_{i} ; a_{i}\left(v_{i}(t)\right)$ and $b_{i}\left(v_{i}(t)\right)$ denote the amplification function and self-inhibition function, respectively; $\tau(t)$ represents the time-varying delay and $0 \leq \tau(t) \leq \tau, \dot{\tau}(t) \leq$ $\widehat{\tau}<1 ; f_{j}\left(v_{j}(t)\right)$ and $g_{j}\left(v_{j}(t-\tau(t))\right)$ are the activation functions without and with time-varying delay, respectively; $I_{i}$ represents the external input to the $i$ th neuron; and $c_{i j}\left(v_{i}(t)\right)$ and $w_{i j}\left(v_{i}(t)\right)$ represent memristive connection weights satisfying

$$
\begin{aligned}
c_{i j}\left(v_{i}(t)\right) & =\frac{\mathbf{W}_{i j}}{\mathbf{C}_{i}} \times \mathrm{SGN}_{i j}, \\
w_{i j}\left(v_{i}(t)\right) & =\frac{\tilde{\mathbf{W}}_{i j}}{\mathbf{C}_{i}} \times \mathrm{SGN}_{i j},
\end{aligned}
$$

in which

$$
\mathrm{SGN}_{i j}= \begin{cases}1, & \text { if } i \neq j, \\ -1, & \text { if } i=j .\end{cases}
$$

$\mathbf{W}_{i j}$ and $\tilde{\mathbf{W}}_{i j}$ stand for the memductances of memristors $\mathbf{M}_{i j}$ and $\tilde{\mathbf{M}}_{i j}$, respectively. $\mathbf{M}_{i j}$ denotes the memristor between the feedback function $f_{j}\left(v_{j}(t)\right)$ and $v_{i}(t) . \tilde{\mathbf{M}}_{i j}$ denotes the memristor between the time-delayed feedback function $g_{j}\left(v_{j}(t-\tau(t))\right)$ and $v_{i}(t)$. According to the current-voltage characteristic of memristor, $c_{i j}\left(v_{i}(t)\right)$ and $w_{i j}\left(v_{i}(t)\right)$ satisfy the following properties:

$$
\begin{gathered}
c_{i j}\left(v_{i}(t)\right)= \begin{cases}\widehat{c}_{i j}, & \left|v_{i}(t)\right|<\gamma_{i}, \\
\check{c}_{i j}, & \left|\mathrm{v}_{i}(t)\right| \geq \gamma_{i},\end{cases} \\
w_{i j}\left(v_{i}(t)\right)= \begin{cases}\widehat{w}_{i j}, & \left|v_{i}(t)\right|<\gamma_{i}, \\
\check{w}_{i j}, & \left|v_{i}(t)\right| \geq \gamma_{i},\end{cases}
\end{gathered}
$$

where the switching jumps $\gamma_{i}>0$, and $\widehat{c}_{i j}, \check{c}_{i j}, \widehat{w}_{i j}$, and $\check{w}_{i j}$ are constants, $i, j \in \mathbb{N}$. 
Throughout this paper, we need the following assumptions:

Assumption 1. $a_{i}(v)$ is continuous and bounded. There exist positive constants $\underline{a}_{i}$ and $\bar{a}_{i}$ such that $0<\underline{a}_{i}<a_{i}(v)<\bar{a}_{i}$, $v \in \mathbb{R}, i \in \mathbb{N}$.

Assumption 2. $b_{i}(v)$ is differentiable, $b_{i}(0)=0$ and there exists a positive constant $l_{i}$ such that $0<l_{i} \leq b_{i}{ }^{\prime}(v), v \in \mathbb{R}, i \in \mathbb{N}$.

Assumption 3. For $i \in \mathbb{N}$ and any two different $x, \mathrm{y} \in \mathbb{R}$, the activation functions $f_{i}$ and $g_{i}$ satisfy Lipschitz conditions, i.e., there exist positive constants $L_{i}$ and $K_{i}$ such that

$$
\begin{gathered}
\left|f_{i}(x)-f_{i}(\mathrm{y})\right| \leq L_{i}|x-\mathrm{y}| \\
\left|g_{i}(x)-g_{i}(\mathrm{y})\right| \leq K_{i}|x-\mathrm{y}|
\end{gathered}
$$

Assumption 4. For $i \in \mathbb{N}$, there exist positive constants $\lambda_{i}, \beta_{i}$, $\delta_{i}$, and $\theta_{i}$ such that the activation functions $f_{i}$ and $g_{i}$ satisfy the following conditions

$$
\begin{gathered}
\left|f_{i}(x)\right| \leq \lambda_{i}|x|+\beta_{i}, \\
\left|g_{i}(x)\right| \leq \delta_{i}|x|+\theta_{i}, \\
\forall x \in \mathbb{R} .
\end{gathered}
$$

By taking the equivalent transformation method [26, 27], the amplification function in the delayed memristive CohenGrossberg neural networks (1) can be well handled. Let us choose a transformation function $h_{i}(v)$ such that

$$
\frac{\mathrm{d}}{\mathrm{d} v} h_{i}(v)=\frac{1}{a_{i}(v)}, \quad h_{i}(0)=0, v \in \mathbb{R}, i \in \mathbb{N}
$$

According to Assumption 1, $1 /\left(a_{i}(v)\right)$ is continuous and positive. Thus, $h_{i}(v)$ is a strictly increasing function. Denoting $x_{i}(t)=h_{i}\left(v_{i}(t)\right)$, thus $\dot{x}_{i}(t)=\left(\dot{v}_{i}(t)\right) /\left(a_{i}\left(v_{i}(t)\right)\right)$ and $v_{i}(t)=h_{i}^{-1}\left(x_{i}(t)\right)$.

Taking the above variable transformations, it follows from (1) that

$$
\begin{aligned}
\dot{x}_{i}(t)= & -\mathrm{b}_{i}\left(h_{i}^{-1}\left(x_{i}(t)\right)\right)+\sum_{j=1}^{n} c_{i j}\left(h_{i}^{-1}\left(x_{i}(t)\right)\right) f_{j}\left(h_{j}^{-1}\left(x_{j}(t)\right)\right) \\
& +\sum_{j=1}^{n} w_{i j}\left(h_{i}^{-1}\left(x_{i}(t)\right)\right) g_{j}\left(h_{j}^{-1}\left(x_{j}(t-\tau(t))\right)\right)+I_{i}, \quad i \in \mathbb{N} .
\end{aligned}
$$

Next, we introduce some important definitions and lemmas for subsequent analysis. For more relevant details, we can refer to [29]. For $\tau>0, C\left([-\tau, 0], \mathbb{R}^{n}\right)$ represents the collection of all continuous functions $\phi:[-\tau, 0] \longrightarrow \mathbb{R}^{n}$ and denotes the Banach space equipped with the norm $\|\phi\|_{C}=$ $\sup _{-\tau<t<0}\|\phi(t)\|$. If $T \in(0,+\infty)$, for any continuous function $x(t):[-\tau, T] \longrightarrow \mathbb{R}^{n}, x_{t}$ can be defined as $x_{t}(s)=x(t+s)$, $s \in[-\tau, 0]$ for all $t \in[0, T]$. Then, $x_{t} \in C\left([-\tau, 0], \mathbb{R}^{n}\right)$.
Definition 1 ([20]). Let set $X \subseteq \mathbb{R}^{n}$, if for each point $x$ of $X$, there corresponds a nonempty set $\mathscr{F}(x) \subseteq \mathbb{R}^{n}$, then $x \longrightarrow \mathscr{F}(x)$ is said to be a set-valued map from $X \longrightarrow$ $\mathbb{R}^{n}$. A set-valued map $\mathscr{F}$ with nonempty values is said to be upper semicontinuous (USC) at $x_{0} \in X$, if for any open set $\mathscr{N}$ containing $\mathscr{F}\left(x_{0}\right)$, there exists a neighborhood $\mathscr{M}$ of $x_{0}$, such that $\mathscr{F}(\mathscr{M}) \subseteq \mathcal{N}$.

Definition 2 ([30]). Consider a differential equation with discontinuous right-hand side $\mathrm{d} x / \mathrm{d} t=f\left(t, x_{t}\right)$. Let us define a Filippov set-valued map $\mathscr{F}\left(t, x_{t}\right)$ (i.e., Filippov regularization) as follows:

$$
\mathscr{F}\left(t, x_{t}\right)=\bigcap_{\tilde{\delta}>0} \bigcap_{\operatorname{meas}(\mathcal{N})=0} \overline{\mathrm{co}}\left[f\left(t, \mathscr{B}\left(x_{t}, \tilde{\delta}\right) \backslash \mathcal{N}\right)\right],
$$

where meas $(\mathcal{N})$ represents the Lebesgue measure of set $\mathscr{N} ; \overline{\mathrm{co}}[\mathbb{E}]$ represents the closure of the convex hull of some set $\mathbb{E}$; intersection is taken over all sets $\mathcal{N}$ of Lebesgue measure zero and over all $\tilde{\delta}>0 ; \mathscr{B}\left(x_{t}, \tilde{\delta}\right):=\left\{\mathrm{y}_{t} \in C([-\tau, 0]\right.$, $\left.\left.\mathbb{R}^{n}\right):\left\|y_{t}-x_{t}\right\|_{C}<\tilde{\delta}\right\}$. A vector-valued function $x(t)$ defined on a nongenerate internal $\mathscr{I} \subseteq \mathbb{R}$ is said to be a Filippov solution of the discontinuous differential equation, if it is absolutely continuous on any compact subinterval $\left[t_{1}, t_{2}\right]$ of $\mathscr{I}$, and also satisfies the differential inclusion $(\mathrm{d} x / \mathrm{d} t) \epsilon$ $\mathscr{F}\left(t, x_{t}\right)$, for almost all $t \in \mathscr{I}$.

Definition 3 ([30]). A vector-valued function $v(t)=$ $\left(v_{1}(t), v_{2}(t), \ldots, v_{n}(t)\right)^{T}:[-\tau, T) \longrightarrow \mathbb{R}^{n}, T \in(0,+\infty)$ is a Filippov solution of system (1) if

(i) $v(t)$ is continuous on $[-\tau, T)$ and absolutely continuous on any compact subinterval of $[0, T)$

(ii) for almost all $t \in[0, T), v(t)$ satisfies the following differential inclusion:

$$
\begin{aligned}
\dot{v}_{i}(t) \in & -a_{i}\left(v_{i}(t)\right)\left[b_{i}\left(v_{i}(t)\right)-\sum_{j=1}^{n} \overline{\mathrm{co}}\left[c_{i j}\left(v_{i}(t)\right)\right] f_{j}\left(v_{j}(t)\right)\right. \\
& \left.-\sum_{j=1}^{n} \overline{\mathrm{co}}\left[w_{i j}\left(v_{i}(t)\right)\right] g_{j}\left(v_{j}(t-\tau(t))\right)-I_{i}\right] \\
\triangleq & \mathscr{F}_{i}\left(t, v_{t}\right), i \in \mathbb{N}
\end{aligned}
$$

where

$$
\begin{gathered}
\overline{\mathrm{CO}}\left[c_{i j}\left(v_{i}(t)\right)\right]= \begin{cases}\widehat{c}_{i j}, & \left|v_{i}(t)\right|<\gamma_{i}, \\
\overline{\mathrm{co}}\left[\underline{c}_{i j}, \bar{c}_{i j}\right], & \left|v_{i}(t)\right|=\gamma_{i}, \\
\check{c}_{i j}, & \left|v_{i}(t)\right|>\gamma_{i},\end{cases} \\
\overline{\mathrm{co}}\left[w_{i j}\left(v_{i}(t)\right)\right]= \begin{cases}\widehat{w}_{i j}, & \left|v_{i}(t)\right|<\gamma_{i}, \\
\overline{\mathrm{CO}}\left[\underline{w}_{i j}, \bar{w}_{i j}\right], & \left|v_{i}(t)\right|=\gamma_{i}, \\
\check{w}_{i j}, & \left|v_{i}(t)\right|>\gamma_{i},\end{cases}
\end{gathered}
$$




$$
\begin{gathered}
\underline{c}_{i j}=\min \left\{\widehat{c}_{i j}, \check{c}_{i j}\right\}, \\
\bar{c}_{i j}=\max \left\{\widehat{c}_{i j}, \check{c}_{i j}\right\}, \\
\underline{w}_{i j}=\min \left\{\widehat{w}_{i j}, \check{w}_{i j}\right\}, \\
\bar{w}_{i j}=\max \left\{\widehat{w}_{i j}, \check{w}_{i j}\right\} .
\end{gathered}
$$

Obviously, the set-valued map $(t, v) \longrightarrow\left(\mathscr{F}_{1}\left(t, v_{t}\right)\right.$, $\left.\mathscr{F}_{2}\left(t, v_{t}\right), \ldots, \mathscr{F}_{n}\left(t, v_{t}\right)\right)^{T}$ is USC and measurable. By using the measurable selection theorem [29], there exist measurable functions $\gamma_{i j}\left(v_{i}(t)\right) \in \overline{\mathrm{co}}\left[c_{i j}\left(v_{i}(t)\right)\right], \eta_{i j}\left(v_{i}(t)\right) \in \overline{\mathrm{co}}\left[w_{i j}\left(v_{i}(t)\right)\right]$, for a.e. $t \geq 0$, such that

$$
\begin{aligned}
\dot{v}_{i}(t)= & -a_{i}\left(v_{i}(t)\right)\left[b_{i}\left(v_{i}(t)\right)-\sum_{j=1}^{n} \gamma_{i j}\left(v_{i}(t)\right) f_{j}\left(v_{j}(t)\right)\right. \\
& \left.-\sum_{j=1}^{n} \eta_{i j}\left(v_{i}(t)\right) g_{j}\left(v_{j}(t-\tau(t))\right)-I_{i}\right] .
\end{aligned}
$$

Based on Definition 3, we can obtain that the Filippov solution $x(t)=\left(x_{1}(t), x_{2}(t), \ldots, x_{n}(t)\right)^{T}$ of system (8) satisfies

$$
\begin{aligned}
\dot{x}_{i}(t) \in & -b_{i}\left(h_{i}^{-1}\left(x_{i}(t)\right)\right)+\sum_{j=1}^{n} \overline{\mathrm{co}}\left[c_{i j}\left(h_{i}^{-1}\left(x_{i}(t)\right)\right)\right] f_{j}\left(h_{j}^{-1}\left(x_{j}(t)\right)\right) \\
& +\sum_{j=1}^{n} \overline{\mathrm{co}}\left[w_{i j}\left(h_{i}^{-1}\left(x_{i}(t)\right)\right)\right] g_{j}\left(h_{j}^{-1}\left(x_{j}(t-\tau(t))\right)\right) \\
& +I_{i}, \quad i \in \mathbb{N},
\end{aligned}
$$

where

$$
\begin{gathered}
\overline{\mathrm{co}}\left[c_{i j}\left(h_{i}^{-1}\left(x_{i}(t)\right)\right)\right]= \begin{cases}\widehat{c}_{i j}, & \left|h_{i}^{-1}\left(x_{i}(t)\right)\right|<\gamma_{i}, \\
\overline{\mathrm{co}}\left[\underline{c}_{i j}, \bar{c}_{i j}\right], & \left|h_{i}^{-1}\left(x_{i}(t)\right)\right|=\gamma_{i}, \\
\check{c}_{i j}, & \left|h_{i}^{-1}\left(x_{i}(t)\right)\right|>\gamma_{i},\end{cases} \\
\overline{\overline{\mathrm{co}}}\left[w_{i j}\left(h_{i}^{-1}\left(x_{i}(t)\right)\right)\right]= \begin{cases}\widehat{w}_{i j}, & \left|h_{i}^{-1}\left(x_{i}(t)\right)\right|<\gamma_{i}, \\
\overline{\mathrm{co}}\left[\underline{w}_{i j}, \bar{w}_{i j}\right], & \left|h_{i}^{-1}\left(x_{i}(t)\right)\right|=\gamma_{i}, \\
\check{w}_{i j}, & \left|h_{i}^{-1}\left(x_{i}(t)\right)\right|>\gamma_{i} .\end{cases}
\end{gathered}
$$

Equivalently, there exist

$$
\begin{aligned}
& \gamma_{i j}\left(h_{i}^{-1}\left(x_{i}(t)\right)\right) \in \overline{\mathrm{co}}\left[c_{i j}\left(h_{i}^{-1}\left(x_{i}(t)\right)\right)\right], \\
& \eta_{i j}\left(h_{i}^{-1}\left(x_{i}(t)\right)\right) \in \overline{\mathrm{co}}\left[w_{i j}\left(h_{i}^{-1}\left(x_{i}(t)\right)\right)\right],
\end{aligned}
$$

for a.e. $t \geq 0$, such that

$$
\begin{aligned}
\dot{x}_{i}(t)= & -b_{i}\left(h_{i}^{-1}\left(x_{i}(t)\right)\right)+\sum_{j=1}^{n} \gamma_{i j}\left(h_{i}^{-1}\left(x_{i}(t)\right)\right) f_{j}\left(h_{j}^{-1}\left(x_{j}(t)\right)\right) \\
& +\sum_{j=1}^{n} \eta_{i j}\left(h_{i}^{-1}\left(x_{i}(t)\right)\right) g_{j}\left(h_{j}^{-1}\left(x_{j}(t-\tau(t))\right)\right)+I_{i} .
\end{aligned}
$$

Definition 4 ([20]). A constant vector $x^{*}=\left(x_{1}^{*}, x_{2}^{*}, \ldots, x_{n}^{*}\right)^{T}$ $\in \mathbb{R}^{n}$ is said to be an equilibrium point of system (8), if and only if,

$$
\begin{aligned}
0 \in & -b_{i}\left(h_{i}^{-1}\left(x_{i}^{*}\right)\right)+\sum_{j=1}^{n} \overline{\mathrm{co}}\left[c_{i j}\left(h_{i}^{-1}\left(x_{i}^{*}\right)\right)\right] f_{j}\left(h_{j}^{-1}\left(x_{j}^{*}\right)\right) \\
& +\sum_{j=1}^{n} \overline{\mathrm{co}}\left[w_{i j}\left(h_{i}^{-1}\left(x_{i}^{*}\right)\right)\right] g_{j}\left(h_{j}^{-1}\left(x_{j}^{*}\right)\right)+I_{i}, \quad i \in \mathbb{N},
\end{aligned}
$$

or, equivalently, there exist $\gamma_{i j}^{*} \in \overline{\mathrm{co}}\left[c_{i j}\left(h_{i}^{-1}\left(x_{i}^{*}\right)\right)\right]$ and $\eta_{i j}^{*} \in \overline{\mathrm{co}}\left[w_{i j}\left(h_{i}^{-1}\left(x_{i}^{*}\right)\right)\right]$ such that

$$
\begin{aligned}
0= & -b_{i}\left(h_{i}^{-1}\left(x_{i}^{*}\right)\right)+\sum_{j=1}^{n} \gamma_{i j}^{*} f_{j}\left(h_{j}^{-1}\left(x_{j}^{*}\right)\right) \\
& +\sum_{j=1}^{n} \eta_{i j}^{*} g_{j}\left(h_{j}^{-1}\left(x_{j}^{*}\right)\right)+I_{i} .
\end{aligned}
$$

Lemma 1 (Kakutani's fixed point theorem [20]). Let $\Omega$ be a compact convex subset of a Banach space $X$, if the setvalued map $\phi: \Omega \longrightarrow P_{k c}(\Omega)$ is an upper semicontinuous convex compact map, then $\phi$ has a fixed point in $\Omega$, i.e., there exists $x \in \Omega$ such that $x \in \phi(x)$.

Lemma 2 (Chain rule [20]). Suppose that $V(\mathrm{y}): \mathbb{R}^{n} \longrightarrow \mathbb{R}$ is $C$-regular, and $\mathrm{y}(t):[0,+\infty) \longrightarrow \mathbb{R}^{n}$ is absolutely continuous on any compact subinterval of $[0,+\infty)$. Then, $y(t)$ and $V(\mathrm{y}(t)):[0,+\infty) \longrightarrow \mathbb{R}$ are differential for a.e. $t \in[0,+\infty)$ and

$$
\frac{\mathrm{d} V(\mathrm{y}(t))}{\mathrm{d} t}=\left\langle\zeta(t), \frac{\mathrm{dy}(t)}{\mathrm{d} t}\right\rangle, \quad \forall \zeta(t) \in \partial V(\mathrm{y}(t))
$$

Here, $\partial V(\mathrm{y})$ represents the Clarke's generalized gradient of $V$ at point $\mathrm{y} \in \mathbb{R}^{n}$.

Lemma 3 ([31, 32]). Suppose that $V(y): \mathbb{R}^{n} \longrightarrow \mathbb{R}$ is $C$ regular, and that $\mathrm{y}(t):[0,+\infty) \longrightarrow \mathbb{R}^{n}$ is absolutely continuous on any compact interval of $[0,+\infty)$. If there exists a 
continuous function $\gamma:[0,+\infty) \longrightarrow \mathbb{R}$, with $\gamma(\rho)>0$ for $\rho \in(0,+\infty)$, such that

$$
\frac{\mathrm{d} V(\mathrm{y}(t))}{\mathrm{d} t} \leq-\gamma(V(\mathrm{y}(t))), \quad \text { for a.e. } t \geq 0,
$$

and

$$
\int_{0}^{V(y(0))} \frac{1}{\gamma(\rho)} \mathrm{d} \rho=t^{*}<+\infty
$$

then, we have $V(\mathrm{y}(t))=0$ for $t \geq t^{*}$. Especially, we have the following conclusions.

(i) If $\gamma(\rho)=K_{1} \rho+K_{2} \rho^{\tilde{\sigma}}$, for all $\rho \in(0,+\infty)$, where $\tilde{\sigma} \in(0,1)$ and $K_{1}, K_{2}>0$, then the settling time is estimated by

$$
t^{*}=\frac{1}{K_{1}(1-\tilde{\sigma})} \ln \frac{K_{1} V^{1-\tilde{\sigma}}(\mathrm{y}(0))+K_{2}}{K_{2}} .
$$

(ii) If $\gamma(\rho)=K \rho^{\tilde{\sigma}}$ and $K>0$, then the settling time is estimated by

$$
t^{*}=\frac{V^{1-\tilde{\sigma}}(\mathrm{y}(0))}{K(1-\tilde{\sigma})} .
$$

4 (Young inequality [33]). Assume that $a>0, b>0$ $p>1,(1 / p)+(1 / q)=1$, then the following inequality holds

$$
a b \leq \frac{1}{p} a^{p}+\frac{1}{q} b^{q} .
$$

Lemma 5 (Hardy inequality [20]). If $a_{1}, a_{2}, \ldots, a_{n}$ are positive numbers and $0<\tau_{1}<\tau_{2}$, then

$$
\left(\sum_{i=1}^{n} a_{i}^{\tau_{2}}\right)^{1 / \tau_{2}} \leq\left(\sum_{i=1}^{n} a_{i}^{\tau_{1}}\right)^{1 / \tau_{1}}
$$

\section{Existence Analysis of Equilibrium Point}

In this section, we discuss the existence of equilibrium point of system (1) using the Kakutani's fixed point theorem of setvalued maps. For further analysis, the following Assumption is needed.
Assumption 5. $\min _{i \in \mathbb{N}}\left\{l_{i} \underline{a}_{i}\right\}-2 \max _{j \in \mathbb{N}}\left\{\sum_{i=1}^{n} c_{i j}^{+} \lambda_{j} \bar{a}_{j}, \sum_{i=1}^{n} w_{i j}^{+}\right.$ $\left.\delta_{j} \bar{a}_{j}\right\}>0$, where $c_{i j}^{+}=\max \left\{\left|\widehat{c}_{i j}\right|,\left|\check{c}_{i j}\right|\right\}$ and $w_{i j}^{+}=\max \left\{\left|\widehat{w}_{i j}\right|\right.$, $\left.\left|\check{w}_{i j}\right|\right\}$.

Theorem 1. Under the Assumptions 1, 2, 4, and 5, the discontinuous differential system (1) has at least one equilibrium point.

Proof. From Assumption 2, we can obtain $b_{i}(v)$ is a monotone increasing function. On the other hand, $h_{i}^{-1}(v)$ is also a monotone increasing function due to the monotone increasing property of $h_{i}(v)$. Thus, if $x^{*}=\left(x_{1}^{*}, x_{2}^{*}, \ldots, x_{n}^{*}\right)^{T}$ is an equilibrium point of system (8), it follows from (17) that

$$
\begin{aligned}
x_{i}^{*} \in & h_{i}\left(b _ { i } ^ { - 1 } \left(\sum_{j=1}^{n} \overline{\mathrm{co}}\left[c_{i j}\left(h_{i}^{-1}\left(x_{i}^{*}\right)\right)\right] f_{j}\left(h_{j}^{-1}\left(x_{j}^{*}\right)\right)\right.\right. \\
& \left.\left.+\sum_{j=1}^{n} \overline{\mathrm{co}}\left[w_{i j}\left(h_{i}^{-1}\left(x_{i}^{*}\right)\right)\right] g_{j}\left(h_{j}^{-1}\left(x_{j}^{*}\right)\right)+I_{i}\right)\right), \quad i \in \mathbb{N} .
\end{aligned}
$$

Let us denote $X=\mathbb{R}^{n}$ and $\|x\|_{1}$ be the norm of $x$, $\forall x \in X$. Obviously, $X$ is a Banach space with the norm $\|\cdot\|_{1}$. Next, we define a compact convex subset $\Omega \subseteq X$ as follows:

$$
\Omega=\left\{\left(x_{1}, x_{2}, \ldots, x_{n}\right)^{T} \in X:\|x\|_{1} \leq r\right\},
$$

where

$$
r=\frac{\sum_{j=1}^{n} \sum_{i=1}^{n}\left(c_{i j}^{+} \beta_{j}+w_{i j}^{+} \theta_{j}\right)+\sum_{i=1}^{n}\left|I_{i}\right|}{\min _{i \in \mathbb{N}}\left\{l_{i} \underline{a}_{i}\right\}-2 \max _{j \in \mathbb{N}}\left\{\sum_{i=1}^{n} c_{i j}^{+} \lambda_{j} \bar{a}_{j}, \sum_{i=1}^{n} w_{i j}^{+} \delta_{j} \bar{a}_{j}\right\}} .
$$

Now, let us define a set-valued map $\varphi: X \longrightarrow P_{k c}(X)$ as follows:

$$
\varphi(x)=\left(\varphi_{1}(x), \varphi_{2}(x), \ldots, \varphi_{n}(x)\right)^{T}, \quad \forall x \in X,
$$

where

$$
\begin{aligned}
\varphi_{i}(x)= & h_{i}\left(b _ { i } ^ { - 1 } \left(\sum_{j=1}^{n} \overline{\mathrm{co}}\left[c_{i j}\left(h_{i}^{-1}\left(x_{i}\right)\right)\right] f_{j}\left(h_{j}^{-1}\left(x_{j}\right)\right)\right.\right. \\
& \left.\left.+\sum_{j=1}^{n} \overline{\operatorname{co}}\left[w_{i j}\left(h_{i}^{-1}\left(x_{i}\right)\right)\right] g_{j}\left(h_{j}^{-1}\left(x_{j}\right)\right)+I_{i}\right)\right), \quad i \in \mathbb{N} .
\end{aligned}
$$


Obviously, the set-valued map $\varphi(x)$ is USC with nonempty compact convex values. In other words, $\varphi(x)$ is an upper semicontinuous convex compact map.

For any $x=\left(x_{1}, x_{2}, \ldots, x_{n}\right)^{T} \in \Omega$ and $\bar{v}=\left(\bar{v}_{1}, \bar{v}_{2}, \ldots\right.$, $\left.\bar{v}_{n}\right)^{T} \in \varphi(x)$, then there exist $\gamma_{i j} \in \overline{\operatorname{co}}\left[c_{i j}\left(h_{i}^{-1}\left(x_{i}\right)\right)\right]$ and $\eta_{i j} \in \overline{\mathrm{co}}\left[w_{i j}\left(h_{i}^{-1}\left(x_{i}\right)\right)\right]$ such that

$$
\begin{aligned}
\bar{v}_{i}= & h_{i}\left(b _ { i } ^ { - 1 } \left(\sum_{j=1}^{n} \gamma_{i j} f_{j}\left(h_{j}^{-1}\left(x_{j}\right)\right)\right.\right. \\
& \left.\left.+\sum_{j=1}^{n} \eta_{i j} g_{j}\left(h_{j}^{-1}\left(x_{j}\right)\right)+I_{i}\right)\right), \quad i \in \mathbb{N} .
\end{aligned}
$$

Because $b_{i}(\cdot)$ and $h_{i}^{-1}(\cdot)$ are all monotone increasing functions, it follows that

$$
\begin{aligned}
b_{i}\left(h_{i}^{-1}\left(\bar{v}_{i}\right)\right)= & \sum_{j=1}^{n} \gamma_{i j} f_{j}\left(h_{j}^{-1}\left(x_{j}\right)\right) \\
& +\sum_{j=1}^{n} \eta_{i j} g_{j}\left(h_{j}^{-1}\left(x_{j}\right)\right)+I_{i}, \quad i \in \mathbb{N} .
\end{aligned}
$$

Thus,

$$
\begin{aligned}
\left|b_{i}\left(h_{i}^{-1}\left(\bar{v}_{i}\right)\right)\right| \leq & \left|\sum_{j=1}^{n} \gamma_{i j} f_{j}\left(h_{j}^{-1}\left(x_{j}\right)\right)\right|+\left|\sum_{j=1}^{n} \eta_{i j} g_{j}\left(h_{j}^{-1}\left(x_{j}\right)\right)\right| \\
& +\left|I_{i}\right|, \quad i \in \mathbb{N} .
\end{aligned}
$$

Since $b_{i}(\cdot)$ and $h_{i}^{-1}(\cdot)$ are differentiable, and $b_{i}(0)=$ $h_{i}(0)=0$, we can obtain

$$
\begin{aligned}
\left|b_{i}\left(h_{i}^{-1}\left(\bar{v}_{i}\right)\right)\right| & =\left|b_{i}\left(h_{i}^{-1}\left(\bar{v}_{i}\right)\right)-b_{i}\left(h_{i}^{-1}(0)\right)\right| \\
& =\left|b_{i}^{\prime}\left(\mathrm{\varrho}_{1}\right)\left(h_{i}^{-1}\left(\bar{v}_{i}\right)-h_{i}^{-1}(0)\right)\right| \\
& =\left|b_{i}^{\prime}\left(\mathrm{\varrho}_{1}\right)\left(h_{i}^{-1}\left(\mathrm{\varrho}_{2}\right)\right)^{\prime}\left(\bar{v}_{i}-0\right)\right| \geq l_{i} \underline{a}_{i}\left|\bar{v}_{i}\right|,
\end{aligned}
$$

where $\mathrm{\varrho}_{1}$ is between $h_{i}^{-1}(0)$ and $h_{i}^{-1}\left(\bar{v}_{i}\right), \mathrm{\varrho}_{2}$ is between 0 and $\bar{v}_{i}$.

Under Assumption 4, we can get

$$
\begin{aligned}
\left|\gamma_{i j} f_{j}\left(h_{j}^{-1}\left(x_{j}\right)\right)\right| & =\left|\gamma_{i j}\right|\left|f_{j}\left(h_{j}^{-1}\left(x_{j}\right)\right)\right| \\
& \leq c_{i j}^{+}\left(\lambda_{j}\left|h_{j}^{-1}\left(x_{j}\right)\right|+\beta_{j}\right) \\
& =c_{i j}^{+} \lambda_{j}\left|h_{j}^{-1}\left(x_{j}\right)-h_{j}^{-1}(0)\right|+c_{i j}^{+} \beta_{j} \\
& =c_{i j}^{+} \lambda_{j}\left|\left(h_{j}^{-1}\left(\varrho_{3}\right)\right)^{\prime}\left(x_{j}-0\right)\right|+c_{i j}^{+} \beta_{j} \\
& \leq c_{i j}^{+} \lambda_{j} \bar{a}_{j}\left|x_{j}\right|+c_{i j}^{+} \beta_{j},
\end{aligned}
$$

where $\varrho_{3}$ is between 0 and $x_{j}$. Similarly,

$$
\left|\eta_{i j} g_{j}\left(h_{j}^{-1}\left(x_{j}\right)\right)\right| \leq w_{i j}^{+} \delta_{j} \bar{a}_{j}\left|x_{j}\right|+w_{i j}^{+} \theta_{j} .
$$

It follows from (32)-(36) that

$$
\begin{aligned}
l_{i} \underline{a}_{i}\left|\bar{v}_{i}\right| \leq & \sum_{j=1}^{n} c_{i j}^{+} \lambda_{j} \bar{a}_{j}\left|x_{j}\right|+\sum_{j=1}^{n} w_{i j}^{+} \delta_{j} \bar{a}_{j}\left|x_{j}\right| \\
& +\sum_{j=1}^{n}\left(c_{i j}^{+} \beta_{j}+w_{i j}^{+} \theta_{j}\right)+\left|I_{i}\right| .
\end{aligned}
$$

By summing up the above inequity, we can get

$$
\begin{aligned}
\sum_{i=1}^{n} l_{i} a_{i}\left|\bar{v}_{i}\right| \leq & \sum_{j=1}^{n} \sum_{i=1}^{n} c_{i j}^{+} \lambda_{j} \bar{a}_{j}\left|x_{j}\right|+\sum_{j=1}^{n} \sum_{i=1}^{n} w_{i j}^{+} \delta_{j} \bar{a}_{j}\left|x_{j}\right| \\
& +\sum_{j=1}^{n} \sum_{i=1}^{n}\left(c_{i j}^{+} \beta_{j}+w_{i j}^{+} \theta_{j}\right)+\sum_{i=1}^{n}\left|I_{i}\right| .
\end{aligned}
$$

Under Assumption 5, it follows that

$$
\begin{aligned}
\min _{i \in \mathbb{N}}\left\{l_{i} \underline{a}_{i}\right\} \sum_{i=1}^{n}\left|\bar{v}_{i}\right| \leq & 2 \max _{j \in \mathbb{N}}\left\{\sum_{i=1}^{n} c_{i j}^{+} \lambda_{j} \bar{a}_{j}, \sum_{i=1}^{n} w_{i j}^{+} \delta_{j} \bar{a}_{j}\right\} \sum_{j=1}^{n}\left|x_{j}\right| \\
& +\sum_{j=1}^{n} \sum_{i=1}^{n}\left(c_{i j}^{+} \beta_{j}+w_{i j}^{+} \theta_{j}\right)+\sum_{i=1}^{n}\left|I_{i}\right| \\
\leq & 2 \max _{j \in \mathbb{N}}\left\{\sum_{i=1}^{n} c_{i j}^{+} \lambda_{j} \bar{a}_{j}, \sum_{i=1}^{n} w_{i j}^{+} \delta_{j} \bar{a}_{j}\right\} r \\
& +\sum_{j=1}^{n} \sum_{i=1}^{n}\left(c_{i j}^{+} \beta_{j}+w_{i j}^{+} \theta_{j}\right)+\sum_{i=1}^{n}\left|I_{i}\right| \\
= & \min _{i \in \mathbb{N}}\left\{l_{i} \underline{a}_{i}\right\} r .
\end{aligned}
$$

It is easy to obtain $\sum_{i=1}^{n}\left|\bar{v}_{i}\right| \leq r$, i.e., $\|\bar{v}\|_{1} \leq r$.

Thus, $\bar{v} \in \Omega$ and $\varphi(x) \in P_{k c}(\Omega)$ for any $x \in \Omega$. Up to now, $\varphi(x)$ satisfies all the conditions in Lemma 1 . Therefore, the set-valued map $\varphi(x)$ exists at least one fixed point $x^{*} \in \Omega$, i.e., $x^{*} \in \varphi\left(x^{*}\right)$. Then, it is easy to obtain that the discontinuous neural networks (1) exists at least one equilibrium point $v^{*}=\left(h_{1}^{-1}\left(x_{1}^{*}\right), h_{2}^{-1}\left(x_{2}^{*}\right), \ldots, h_{n}{ }^{-1}\left(x_{n}^{*}\right)\right)^{T}$. The proof is completed.

Remark 1. The novel Kakutani's fixed point theorem of set-valued maps is used to discuss the existence of equilibrium point for memristive Cohen-Grossberg neural networks with time-varying delay $[20,32]$. Compared with $[20,32]$, the factor of amplification function are considered and the activation functions can be unbounded in the neural networks (1). Thus, the neural networks in this paper is more general. On the other hand, the method by using the equivalent transformation system (8) is effective and novel. In one word, the method of proof and theoretical 
results in Theorem 1 are novel and extend the scope of the previous work.

\section{Finite-Time Stabilization}

In this section, we will discuss the FTS of system (1), i.e., stabilize the system states to the equilibrium point in finite time. In order to realize this goal, two kinds of discontinuous controllers are designed. By adding the discontinuous controller $u_{i}(t)$, we obtain the following discontinuous controlled system from (1)

$$
\begin{aligned}
\dot{v}_{i}(t)= & -a_{i}\left(v_{i}(t)\right)\left[b_{i}\left(v_{i}(t)\right)-\sum_{j=1}^{n} c_{i j}\left(v_{i}(t)\right) f_{j}\left(v_{j}(t)\right)\right. \\
& \left.-\sum_{j=1}^{n} w_{i j}\left(v_{i}(t)\right) g_{j}\left(v_{j}(t-\tau(t))\right)-I_{i}-u_{i}(t)\right], \quad i \in \mathbb{N} .
\end{aligned}
$$

By taking the variable transformation $\mathrm{y}(t)=x(t)-x^{*}=$ $\left(\mathrm{y}_{1}(t), \mathrm{y}_{2}(t), \ldots, \mathrm{y}_{n}(t)\right)^{T}$, it follows from (40) that

$$
\begin{aligned}
\dot{\mathrm{y}}_{i}(t)= & -\left[b_{i}\left(h_{i}^{-1}\left(x_{i}(t)\right)\right)-b_{i}\left(h_{i}^{-1}\left(x_{i}^{*}\right)\right)\right] \\
& +\sum_{j=1}^{n}\left[\gamma_{i j}\left(h_{i}^{-1}\left(x_{i}(t)\right)\right) f_{j}\left(h_{j}^{-1}\left(x_{j}(t)\right)\right)\right. \\
& \left.-\gamma_{i j}^{*} f_{j}\left(h_{j}^{-1}\left(x_{j}^{*}\right)\right)\right] \\
& +\sum_{j=1}^{n}\left[\eta_{i j}\left(h_{i}^{-1}\left(x_{i}(t)\right)\right) g_{j}\left(h_{j}^{-1}\left(x_{j}(t-\tau(t))\right)\right)\right. \\
& \left.-\eta_{i j}^{*} g_{j}\left(h_{j}^{-1}\left(x_{j}^{*}\right)\right)\right]+u_{i}(t), \quad i \in \mathbb{N} .
\end{aligned}
$$

For further analysis, the following important inequalities are needed. Let $e(t)=\left(e_{1}(t), e_{2}(t), \ldots, e_{n}(t)\right)^{T}$, where $e_{i}(t)=$ $v_{i}(t)-v_{i}^{*}, i \in \mathbb{N}$. Since $h_{i}^{-1}(\cdot)$ is differentiable, we can get

$$
\begin{aligned}
e_{i}(t) & =h_{i}^{-1}\left(x_{i}(t)\right)-h_{i}^{-1}\left(x_{i}^{*}\right) \\
& =\left(h_{i}^{-1}(\bar{\xi})\right)^{\prime}\left(x_{i}(t)-x_{i}^{*}\right) \\
& =\left(h_{i}^{-1}(\bar{\xi})\right)^{\prime} \mathrm{y}_{i}(t),
\end{aligned}
$$

where $\bar{\xi}$ is between $x_{i}(t)$ and $x_{i}^{*}$. From $(42)$ and $\left(h_{i}^{-1}(\bar{\xi})\right)^{\prime}=$ $a_{i}(\bar{\xi})>0$, it follows that sign $\left(e_{i}(t)\right)=\operatorname{sign}\left(\mathrm{y}_{i}(t)\right)$.

Similar to (42), we can get

$$
\begin{aligned}
-\left|\mathrm{e}_{i}(t-\tau(t))\right| & =-\left|h_{i}^{-1}\left(x_{i}(t-\tau(t))\right)-h_{i}^{-1}\left(x_{i}^{*}\right)\right| \\
& =-\left|\left(h_{i}^{-1}(\tilde{\xi})\right)^{\prime}\left(x_{i}(t-\tau(t))-x_{i}^{*}\right)\right| \\
& \leq-\underline{a}_{i}\left|\mathrm{y}_{i}(t-\tau(t))\right|,
\end{aligned}
$$

where $\tilde{\xi}$ is between $x_{i}(t-\tau(t))$ and $x_{i}^{*}$.
Using (42), it follows that

$$
\begin{aligned}
-e_{i}(t) \operatorname{sign}\left(\mathrm{y}_{i}(t)\right) & =-\left(h_{i}^{-1}(\bar{\xi})\right)^{\prime} \mathrm{y}_{i}(t) \operatorname{sign}\left(\mathrm{y}_{i}(t)\right) \\
& \leq-\underline{a}_{i}\left|\mathrm{y}_{i}(t)\right| .
\end{aligned}
$$

Since $b_{i}(\cdot)$ and $h_{i}^{-1}(\cdot)$ are all differentiable, $b_{i}\left(h_{i}^{-1}(\cdot)\right)$ is also differentiable. By using the Lagrange mean value theorem, it follows that

$$
\begin{aligned}
-\operatorname{sign} & \left(\mathrm{y}_{i}(t)\right)\left[b_{i}\left(h_{i}^{-1}\left(x_{i}(t)\right)\right)-b_{i}\left(h_{i}^{-1}\left(x_{i}^{*}\right)\right)\right] \\
& =-\operatorname{sign}\left(\mathrm{y}_{i}(t)\right) b_{i}^{\prime}\left(\xi_{1}\right)\left(h_{i}^{-1}\left(x_{i}(t)\right)-h_{i}^{-1}\left(x_{i}^{*}\right)\right) \\
& =-\operatorname{sign}\left(\mathrm{y}_{i}(t)\right) b_{i}^{\prime}\left(\xi_{1}\right)\left(h_{i}^{-1}\left(\xi_{2}\right)\right)^{\prime}\left(x_{i}(t)-x_{i}^{*}\right) \\
& \leq-l_{i} \underline{a}_{i}\left|\mathrm{y}_{i}(t)\right|,
\end{aligned}
$$

where $\xi_{1}$ is between $h_{i}^{-1}\left(x_{i}(t)\right)$ and $h_{i}^{-1}\left(x_{i}^{*}\right), \xi_{2}$ is between $x_{i}(t)$ and $x_{i}^{*}$.

From the proof of Theorem 1, we can know that the equilibrium point $x^{*}=\left(x_{1}^{*}, x_{2}^{*}, \ldots, x_{n}^{*}\right)^{T} \in \Omega$. Therefore, there exist positive constants $M_{i}$ and $N_{i}$ such that

$$
\left|f_{i}\left(h_{i}^{-1}\left(x_{i}^{*}\right)\right)\right| \leq M_{i},\left|g_{i}\left(h_{i}^{-1}\left(x_{i}^{*}\right)\right)\right| \leq N_{i}, \quad i \in \mathbb{N} .
$$

Under the Assumption 3 and (46), we can obtain

$$
\begin{aligned}
&\left|\gamma_{i j}\left(h_{i}^{-1}\left(x_{i}(t)\right)\right) f_{j}\left(h_{j}^{-1}\left(x_{j}(t)\right)\right)-\gamma_{i j}^{*} f_{j}\left(h_{j}^{-1}\left(x_{j}^{*}\right)\right)\right| \\
& \leq \mid \gamma_{i j}\left(h_{i}^{-1}\left(x_{i}(t)\right)\right) f_{j}\left(h_{j}^{-1}\left(x_{j}(t)\right)\right) \\
& \quad-\gamma_{i j}\left(h_{i}^{-1}\left(x_{i}(t)\right)\right) f_{j}\left(h_{j}^{-1}\left(x_{j}^{*}\right)\right) \mid \\
&+\left|\gamma_{i j}\left(h_{i}^{-1}\left(x_{i}(t)\right)\right) f_{j}\left(h_{j}^{-1}\left(x_{j}^{*}\right)\right)-\gamma_{i j}^{*} f_{j}\left(h_{j}^{-1}\left(x_{j}^{*}\right)\right)\right| \\
& \leq c_{i j}^{+} L_{j} \bar{a}_{j}\left|\mathrm{y}_{j}(t)\right|+\left|\widehat{c}_{i j}-\check{c}_{i j}\right| M_{j} .
\end{aligned}
$$

Similar to (47), it follows that

$$
\begin{gathered}
\left|\eta_{i j}\left(h_{i}^{-1}\left(x_{i}(t)\right)\right) g_{j}\left(h_{j}^{-1}\left(x_{j}(t-\tau(t))\right)\right)-\eta_{i j}^{*} g_{j}\left(h_{j}^{-1}\left(x_{j}^{*}\right)\right)\right| \\
\leq w_{i j}^{+} K_{j} \bar{a}_{j}\left|\mathrm{y}_{j}(t-\tau(t))\right|+\left|\widehat{w}_{i j}-\check{w}_{i j}\right| N_{j} .
\end{gathered}
$$

4.1. Discontinuous State Feedback Controller with TimeVarying Delay. In order to realize the FTS of system (1), the 
following discontinuous state feedback controller with timevarying delay is designed.

$$
\begin{aligned}
u_{i}(t)= & -p_{i} e_{i}(t)-q_{i} \operatorname{sign}\left(e_{i}(t)\right) \\
& -r_{i} \operatorname{sign}\left(e_{i}(\mathrm{t})\right) \sum_{j=1}^{n}\left|e_{j}(t-\tau(t))\right|, \quad i \in \mathbb{N},
\end{aligned}
$$

where $p_{i}, q_{i}$, and $r_{i}$ are positive constants to be determined later. In this section, we will use the famous finite-time stability theory to study the FTS of system (1). In the following, we further assume

Assumption 6. $r_{i} \check{a} \geq \max _{j \in \mathbb{N}}\left\{w_{i j}^{+} K_{j} \bar{a}_{j}\right\}, \quad i \in \mathbb{N}$, where $\check{a}=$ $\min _{i \in \mathbb{N}}\left\{\underline{a}_{i}\right\}$.

Theorem 2. Suppose that Assumptions 1-6 hold. If $p>1$, $\varpi_{1}=p\left(\min _{i \in \mathbb{N}}\left\{l_{i} \underline{a}_{i}+p_{i} \underline{a}_{i}\right\}-n \cdot \max _{i, j \in \mathbb{N}}\left\{c_{i j}^{+} L_{j} \bar{a}_{j}\right\}\right)>0$, and $\Phi_{2}=p \min _{i \in \mathbb{N}}\left\{q_{i}-\sum_{j=1}^{n}\left(\left|\widehat{c}_{i j}-\check{c}_{i j}\right| M_{j}+\left|\widehat{w}_{i j}-\check{w}_{i j}\right| N_{j}\right)\right\}>0$.

Then, the discontinuous neural networks (1) can be stabilized in a finite time with the discontinuous state feedback controller (49). The settling time for FTS can be estimated by

$$
T^{*}=\frac{p}{\Phi_{1}} \ln \frac{\omega_{1} V^{1 / p}(0)+\omega_{2}}{\Phi_{2}} .
$$

Proof. Let us consider the Lyapunov function

$$
V(t)=\sum_{i=1}^{n}\left|\mathrm{y}_{i}(t)\right|^{p}
$$

It can be easily verified that $V(t)$ is $\mathrm{C}$-regular. Therefore, we can calculate the derivative of $V(t)$ along the solution of (41) by using Lemma 2 ,

$$
\begin{aligned}
\frac{\mathrm{d} V(t)}{\mathrm{d} t}= & \sum_{i=1}^{n} p\left|\mathrm{y}_{i}(t)\right|^{p-1} \operatorname{sign}\left(\mathrm{y}_{i}(t)\right) \dot{\mathrm{y}}_{i}(t) \\
= & \sum_{i=1}^{n} p\left|\mathrm{y}_{i}(t)\right|^{p-1} \operatorname{sign}\left(\mathrm{y}_{i}(t)\right)\left\{-\left[b_{i}\left(h_{i}^{-1}\left(x_{i}(t)\right)\right)\right.\right. \\
& \left.-b_{i}\left(h_{i}^{-1}\left(x_{i}^{*}\right)\right)\right]+\sum_{j=1}^{n}\left[\gamma_{i j}\left(h_{i}^{-1}\left(x_{i}(t)\right)\right) f_{j}\left(h_{j}^{-1}\left(x_{j}(t)\right)\right)\right. \\
& \left.-\gamma_{i j}^{*} f_{j}\left(h_{j}^{-1}\left(x_{j}^{*}\right)\right)\right] \\
& +\sum_{j=1}^{n}\left[\eta_{i j}\left(h_{i}^{-1}\left(x_{i}(t)\right)\right) g_{j}\left(h_{j}^{-1}\left(x_{j}(t-\tau(t))\right)\right)\right. \\
& \left.-\eta_{i j}^{*} g_{j}\left(h_{j}^{-1}\left(x_{j}^{*}\right)\right)\right]-p_{i} e_{i}(t)-q_{i} \operatorname{sign}\left(e_{i}(t)\right) \\
& \left.-r_{i} \operatorname{sign}\left(e_{i}(t)\right) \sum_{j=1}^{n}\left|e_{j}(t-\tau(t))\right|\right\} .
\end{aligned}
$$

Under Assumption 6 and expressions (42)-(48), we can get

$$
\begin{aligned}
\frac{\mathrm{d} V(t)}{\mathrm{d} t} \leq & \sum_{i=1}^{n} p\left|\mathrm{y}_{i}(t)\right|^{p-1}\left\{-\left(l_{i} \underline{a}_{i}+p_{i} \underline{a}_{i}\right)\left|\mathrm{y}_{i}(t)\right|\right. \\
& +\sum_{j=1}^{n} c_{i j}^{+} L_{j} \bar{a}_{j}\left|\mathrm{y}_{j}(t)\right|+\max _{j \in \mathbb{N}}\left\{w_{i j}^{+} K_{j} \bar{a}_{j}\right\} \sum_{j=1}^{n}\left|\mathrm{y}_{j}(t-\tau(t))\right| \\
& -r_{i} \check{a} \sum_{j=1}^{n}\left|\mathrm{y}_{j}(t-\tau(t))\right|+\left(\sum _ { j = 1 } ^ { n } \left(\left|\widehat{c}_{i j}-\check{c}_{i j}\right| M_{j}\right.\right. \\
& \left.\left.\left.+\left|\widehat{w}_{i j}-\check{w}_{i j}\right| N_{j}\right)-q_{i}\right)\right\} \\
\leq & -\min _{i \in \mathbb{N}}\left\{l_{i} \underline{a}_{i}+p_{i} \underline{a}_{i}\right\} \cdot p \sum_{i=1}^{n}\left|\mathrm{y}_{i}(t)\right|^{p}+\max _{i, j \in \mathbb{N}}\left\{c_{i j}^{+} L_{j} \bar{a}_{j}\right\} \\
& \cdot p \sum_{i=1}^{n} \sum_{j=1}^{n}\left|\mathrm{y}_{i}(t)\right|^{p-1}\left|\mathrm{y}_{j}(t)\right| \\
& -p \min _{i \in \mathbb{N}}\left\{q_{i}-\sum_{j=1}^{n}\left(\left|\widehat{c}_{i j}-\check{c}_{i j}\right| M_{j}\right.\right. \\
& \left.\left.+\left|\widehat{w}_{i j}-\check{w}_{i j}\right| N_{j}\right)\right\} \sum_{i=1}^{n}\left|\mathrm{y}_{i}(t)\right|^{p-1} .
\end{aligned}
$$

According to Lemma 4,

$$
\left|\mathrm{y}_{i}(t)\right|^{p-1}\left|\mathrm{y}_{j}(t)\right| \leq \frac{p-1}{p}\left|\mathrm{y}_{i}(t)\right|^{p}+\frac{1}{p}\left|\mathrm{y}_{j}(t)\right|^{p} .
$$

Then,

$$
\begin{aligned}
p \sum_{i=1}^{n} \sum_{j=1}^{n}\left|\mathrm{y}_{i}(t)\right|^{p-1}\left|\mathrm{y}_{j}(t)\right| & \leq n(p-1) \sum_{i=1}^{n}\left|\mathrm{y}_{i}(t)\right|^{p}+n \sum_{j=1}^{n}\left|\mathrm{y}_{j}(t)\right|^{p} \\
& =n p \sum_{i=1}^{n}\left|\mathrm{y}_{i}(t)\right|^{p} .
\end{aligned}
$$

By Lemma 5, we can deduce the following inequality

$$
\sum_{i=1}^{n}\left|\mathrm{y}_{i}(t)\right|^{p^{-1}} \geq\left(\sum_{i=1}^{n}\left|\mathrm{y}_{i}(t)\right|^{p}\right)^{(p-1) / p}
$$


It follows from (53)-(56) that

$$
\begin{aligned}
\frac{\mathrm{d} V(t)}{\mathrm{d} t} \leq & -p\left(\min _{i \in \mathbb{N}}\left\{l_{i} \underline{a}_{i}+p_{i} \underline{a}_{i}\right\}-n \cdot \max _{i, j \in \mathbb{N}}\left\{c_{i j}^{+} L_{j} \bar{a}_{j}\right\}\right) \sum_{i=1}^{n}\left|\mathrm{y}_{i}(t)\right|^{p} \\
& -p \min _{i \in \mathbb{N}}\left\{q_{i}-\sum_{j=1}^{n}\left(\left|\widehat{c}_{i j}-\check{c}_{i j}\right| M_{j}+\mid \widehat{w}_{i j}\right.\right. \\
& \left.\left.-\check{w}_{i j} \mid N_{j}\right)\right\}\left(\sum_{i=1}^{n}\left|\mathrm{y}_{i}(t)\right|^{p}\right)^{(p-1) / p} \\
= & -\omega_{1} V(t)-\omega_{2} V(t)^{(p-1) / p} .
\end{aligned}
$$

Under the conditions $\Phi_{1}>0$ and $\omega_{2}>0$, the FTS of discontinuous neural networks (8) can be realized using Lemma 3. In addition, the settling time can be calculated as follows:

$$
T^{*}=\frac{p}{\omega_{1}} \ln \frac{\omega_{1} V^{1 / p}(0)+\omega_{2}}{\omega_{2}} .
$$

In other words, $V(t)=0, \forall t \geq T^{*}$. It follows that

$$
\mathrm{y}(t)=x(t)-x^{*}=0, \quad \forall t \geq T^{*} .
$$

It follows from (42) that

$$
e_{i}(t)=\left(h_{i}^{-1}(\bar{\xi})\right)^{\prime} \mathrm{y}_{i}(t) \leq \bar{a}_{i}\left|\mathrm{y}_{i}(t)\right|, \quad i \in \mathbb{N} .
$$

Thus, $e(t)=0, \forall t \geq T^{*}$. Therefore, the FTS of delayed memristive Cohen-Grossberg neural networks (1) with the discontinuous state feedback controller (49) can be realized with the settling time $T^{*}$.

The proof is completed.

Similar to Theorem 2, it is easy to obtain the following corollary by a similar proof.

Corollary 1. Suppose that Assumptions 1-6 hold. If $p>1$, $\varpi_{1}=p\left(\min _{i \in \mathbb{N}}\left\{l_{i} \underline{a}_{i}+p_{i} \underline{a}_{i}\right\}-n \cdot \max _{i, j \in \mathbb{N}}\left\{c_{i j}^{+} L_{j} \bar{a}_{j}\right\}\right)=0$, and $\omega_{2}=p \min _{i \in \mathbb{N}}\left\{q_{i}-\sum_{j=1}^{n}\left(\left|\widehat{c}_{i j}-\check{c}_{i j}\right| M_{j}+\left|\widehat{w}_{i j}-\check{w}_{i j}\right| N_{j}\right)\right\}>0$.

Then, the discontinuous neural networks (1) with the discontinuous state feedback controller (49) can realize FTS. The settling time for FTS can be estimated by

$$
T^{*}=\frac{p V^{1 / p}(0)}{\omega_{2}} .
$$

Remark 2. When compared with conventional continuous state feedback controllers, the discontinuous state feedback controller (49) contains discontinuous terms $-q_{i} \operatorname{sign}\left(e_{i}(t)\right)$ and $-r_{i} \operatorname{sign}\left(e_{i}(t)\right) \cdot \sum_{j=1}^{n}\left|e_{j}(t-\tau(t))\right|$. It is easy to obtain that different terms in this controller play different roles. In other words, $-r_{i} \operatorname{sign}\left(e_{i}(t)\right) \sum_{j=1}^{n}\left|e_{j}(t-\tau(t))\right|$ can handle the influence of time-varying delay, $-p_{i} e_{i}(t)$ and $-q_{i} \operatorname{sign}\left(e_{i}(t)\right)$ are used to guarantee the FTS. It is worth noting that the expressions (59) and (60) are important to obtain the FTS of the system (1) when we have proved the FTS of the discontinuous system (8).

Remark 3. It is effective to handle the uncertain differences of Filippov solutions by designing discontinuous controllers $[16,20,27,32]$. From (50) and (61), we can know that the settling time for FTS can be controlled by the tunable constant $p$. However, this goal was realized by adding the related term in the controllers in $[16,27,32]$, such as the term $-n_{i} \mathrm{e}_{i}(t)\left|\mathrm{e}_{i}(t)\right|^{\sigma-1}$ in [16]. On the other hand, the neural networks in this paper is more general than $[16,20,27,32]$. Thus, the discontinuous controller (49) and theoretical results obtained in Theorem 2 are novel.

4.2. Discontinuous State Feedback Controller without TimeVarying Delay. In this section, we design the following discontinuous state feedback controller without timevarying delay,

$$
u_{i}(t)=-s_{i} e_{i}(t)-\pi_{i} \operatorname{sign}\left(e_{i}(t)\right), \quad i \in \mathbb{N}
$$

where $s_{i}$ and $\pi_{i}$ are the gain coefficients to be determined later. Besides, the analysis method without using the finitetime stability theory will be presented to investigate the FTS of (1).

Based on Assumption 1, we need to further assume that Assumption 7. $\bar{a}_{i}<1$, for $v \in \mathbb{R}, i \in \mathbb{N}$.

Theorem 3. Suppose Assumptions 1-5 and 7 hold. The gain coefficients $s_{i}$ and $\pi_{i}$ satisfy the following conditions,

$$
\widehat{\omega}=\min _{i \in \mathbb{N}}\left\{l_{i} \underline{a}_{i}+s_{i} \underline{a}_{i}\right\}-n \max _{i, j \in \mathbb{N}}\left\{c_{i j}^{+} L_{j} \bar{a}_{j}+\frac{\alpha_{i j} \bar{a}_{j}}{1-\widehat{\tau}}\right\} \geq 0,
$$

and

$$
\varpi^{*}=n \min _{i \in \mathbb{N}}\left\{\pi_{i}-\sum_{j=1}^{n}\left(\left|\widehat{c}_{i j}-\check{c}_{i j}\right| M_{j}+\left|\widehat{w}_{i j}-\check{w}_{i j}\right| N_{j}\right)\right\}>0,
$$

where $\alpha_{i j}=w_{i j}^{+} K_{j} \bar{a}_{j} \underline{a}_{j}$. Then, the memristive CohenGrossberg neural networks with time-varying delay (1) can be finite-time stabilized via the discontinuous state feedback controller without time-varying delay (62). Furthermore, the settling time can be calculated as follows:

$$
T^{*}=\frac{V(0)}{\omega^{*}} .
$$


Proof. Consider the following Lyapunov function

$$
V(t)=\sum_{i=1}^{n}\left|\mathrm{y}_{i}(t)\right|+\sum_{i=1}^{n} \sum_{j=1}^{n} \frac{\alpha_{i j}}{1-\widehat{\tau}} \int_{t-\tau(t)}^{t}\left|e_{j}(s)\right| \mathrm{d} s .
$$

It is easy to verify that $V(t)$ is C-regular. The derivative of $V(t)$ along the solution of (41) can be calculated by using Lemma 2,

$$
\begin{aligned}
\dot{V}(t)= & \sum_{i=1}^{n} \operatorname{sign}\left(\mathrm{y}_{i}(t)\right) \dot{\mathrm{y}}_{i}(t)+\sum_{i=1}^{n} \sum_{j=1}^{n} \frac{\alpha_{i j}}{1-\widehat{\tau}}\left|e_{j}(t)\right| \\
& -\sum_{i=1}^{n} \sum_{j=1}^{n} \frac{\alpha_{i j}}{1-\widehat{\tau}}\left|e_{j}(t-\tau(t))\right|(1-\dot{\tau}(t)) \\
\leq & \sum_{i=1}^{n} \operatorname{sign}\left(\mathrm{y}_{i}(t)\right)\left\{-\left[b_{i}\left(h_{i}^{-1}\left(x_{i}(t)\right)\right)-b_{i}\left(h_{i}^{-1}\left(x_{i}^{*}\right)\right)\right]\right. \\
& +\sum_{j=1}^{n}\left[\gamma_{i j}\left(h_{i}^{-1}\left(x_{i}(t)\right)\right) f_{j}\left(h_{j}^{-1}\left(x_{j}(t)\right)\right)\right. \\
& \left.-\gamma_{i j}^{*} f_{j}\left(h_{j}^{-1}\left(x_{j}^{*}\right)\right)\right] \\
& +\sum_{j=1}^{n}\left[\eta_{i j}\left(h_{i}^{-1}\left(x_{i}(t)\right)\right) g_{j}\left(h_{j}^{-1}\left(x_{j}(t-\tau(t))\right)\right)\right. \\
& \left.\left.-\eta_{i j}^{*} g_{j}\left(h_{j}^{-1}\left(x_{j}^{*}\right)\right)\right]-s_{i} e_{i}(t)-\pi_{i} \operatorname{sign}\left(e_{i}(t)\right)\right\} \\
& +\sum_{i=1}^{n} \sum_{j=1}^{n} \frac{\alpha_{i j}}{1-\widehat{\tau}}\left|e_{j}(t)\right|-\sum_{i=1}^{n} \sum_{j=1}^{n} \alpha_{i j}\left|e_{j}(t-\tau(t))\right| .
\end{aligned}
$$

By using (42)-(48), we can get

$$
\begin{aligned}
\frac{\mathrm{d} V(t)}{\mathrm{d} t} \leq & \sum_{i=1}^{n}\left\{-\left(l_{i} \underline{a}_{i}+s_{i} \underline{a}_{i}\right)\left|\mathrm{y}_{i}(t)\right|+\sum_{j=1}^{n} c_{i j}^{+} L_{j} \bar{a}_{j}\left|\mathrm{y}_{j}(t)\right|\right. \\
& +\sum_{j=1}^{n} w_{i j}^{+} K_{j} \bar{a}_{j}\left|\mathrm{y}_{j}(t-\tau(t))\right| \\
& \left.+\left(\sum_{j=1}^{n}\left(\left|\widehat{c}_{i j}-\check{c}_{i j}\right| M_{j}+\left|\widehat{w}_{i j}-\check{w}_{i j}\right| N_{j}\right)-\pi_{i}\right)\right\} \\
& +\sum_{i=1}^{n} \sum_{j=1}^{n} \frac{\alpha_{i j} \bar{a}_{j}}{1-\widehat{\tau}}\left|\mathrm{y}_{j}(t)\right|-\sum_{i=1}^{n} \sum_{j=1}^{n} \alpha_{i j} \underline{a}_{j}\left|\mathrm{y}_{j}(t-\tau(t))\right| \\
\leq & -\left(\min _{i \in \mathbb{N}}\left\{l_{i} \underline{a}_{i}+s_{i} \underline{a}_{i}\right\}-n \max _{i, j \in \mathbb{N}}\left\{c_{i j}^{+} L_{j} \bar{a}_{j}+\frac{\alpha_{i j} \bar{a}_{j}}{1-\widehat{\tau}}\right\}\right) \sum_{i=1}^{n}\left|\mathrm{y}_{i}(t)\right| \\
& -n \min _{i \in \mathbb{N}}\left\{\pi_{i}-\sum_{j=1}^{n}\left(\left|\widehat{c}_{i j}-\check{c}_{i j}\right| M_{j}+\left|\widehat{w}_{i j}-\check{w}_{i j}\right| N_{j}\right)\right\} \\
\leq & -\omega^{*} .
\end{aligned}
$$

Next, the FTS of discontinuous system (1) can be studied without using the finite-time stability theory. As proposed in [34], we can get $V(t)=0$ for $t \geq T^{*}=V(0) /$ $\omega^{*}$. By taking a similar analysis in Theorem 2, we can obtain that the FTS of discontinuous neural networks (1) can be realized via the discontinuous controller without time-varying delay (62) with the settling time $T^{*}$. The proof is completed.

Remark 4. In this paper, we design two different kinds of state feedback controllers whether including time-varying delay. When compared with the discontinuous controller with time-varying delay (49), the discontinuous controller without time-varying delay (62) is simpler. However, in Theorem 2, we do not need the conditions $\dot{\tau}(t) \leq \widehat{\tau}<1$ and Assumption 7 , which are essential conditions in Theorem 3. Thus, the results in Theorem 2 are less conservative. Besides, two different kinds of analysis methods whether using finitetime stability theory are utilized. In practice, the researchers can choose the suitable controller and analysis method according to practical needs. On the other hand, it is worth noting that the expressions (42)-(44) are important to connect the discontinuous systems (1) and (8) in the proof of Theorem 2 and Theorem 3.

Remark 5. There exist a few papers considering the FTS of memristor-based neural networks [20, 23, 28, 35]. However, the authors in $[20,23,35]$ did not consider the factor of time-varying delay and amplification function simultaneously. In [28], the finite-time stability and synchronization of a class of memristor-based fractional-order Cohen-Grossberg neural network with time delay was discussed. However, the activation functions are bounded and the time delay is constant in [28]. To the best of our knowledge, there is little work concerning the FTS of memristive Cohen-Grossberg neural networks with time-varying delay. Therefore, the theoretical results obtained in this paper are novel.

\section{Numerical Examples}

In this section, we take two numerical examples to illustrate the correctness of theoretical results provided in this paper.

Example 1. Consider the 2-D delayed memristive CohenGrossberg neural networks as follows:

$$
\begin{aligned}
\dot{v}_{i}(t)= & -a_{i}\left(v_{i}(t)\right)\left[b_{i}\left(v_{i}(t)\right)-\sum_{j=1}^{2} c_{i j}\left(v_{i}(t)\right) f_{j}\left(v_{j}(t)\right)\right. \\
& \left.-\sum_{j=1}^{2} w_{i j}\left(v_{i}(t)\right) g_{j}\left(v_{j}(t-\tau(t))\right)-I_{i}\right],
\end{aligned}
$$




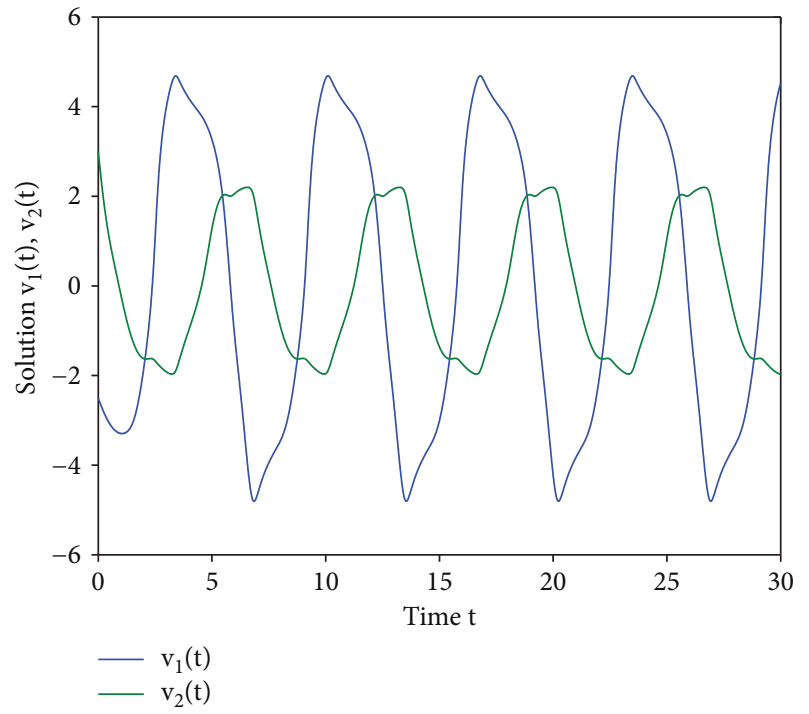

(a)

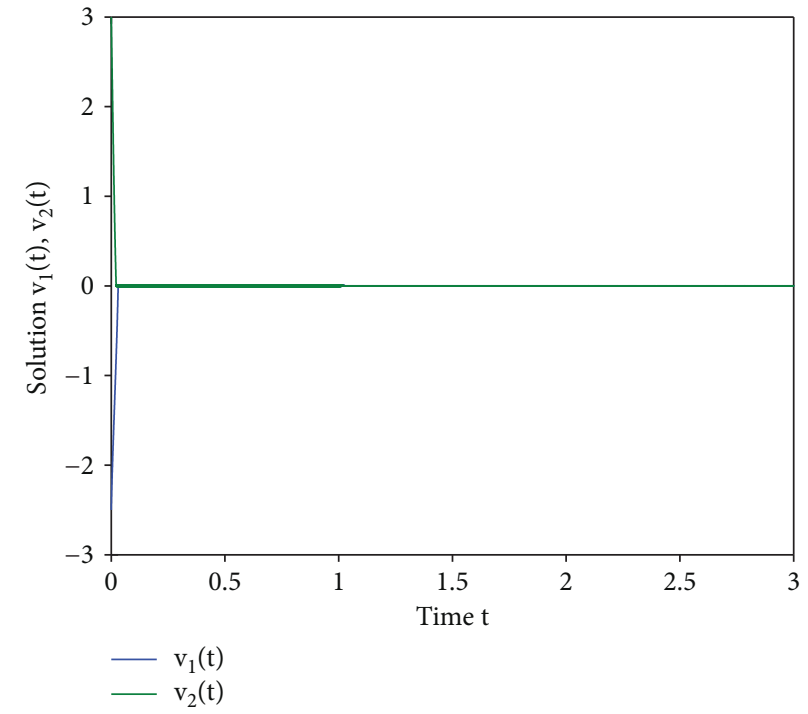

(b)

FIGURE 1: (a) The trajectories of state variables $v_{1}(t)$ and $v_{2}(t)$ in (69) without any controllers. (b) The trajectories of state variables $v_{1}(t)$ and $v_{2}(t)$ in (69) with the discontinuous state feedback controller (49).

where

$$
\begin{aligned}
& a_{i}\left(v_{i}(t)\right)=1.5+0.5 \sin \left(v_{i}(t)\right), \\
& f_{i}(\tilde{\theta})=\tanh (\tilde{\theta}) \\
& g_{i}(\tilde{\theta})=2 \tanh (\tilde{\theta}) \text {, } \\
& \tau(t)=1, \\
& I_{i}=0, \tilde{\theta} \in \mathbb{R}, \\
& i=1,2 \text {, } \\
& b_{1}\left(v_{1}(t)\right)=v_{1}(t) \text {, } \\
& b_{2}\left(v_{2}(t)\right)=v_{2}(t) \text {, } \\
& c_{11}\left(v_{1}(t)\right)=1 . \\
& c_{12}\left(v_{1}(t)\right)= \begin{cases}-0.5, & \left|v_{1}(t)\right|<0, \\
-0.3, & \left|v_{1}(t)\right| \geq 0\end{cases} \\
& c_{21}\left(v_{2}(t)\right)= \begin{cases}-0.2, & \left|v_{2}(t)\right|<0, \\
-0.6, & \left|v_{2}(t)\right| \geq 0,\end{cases} \\
& c_{22}\left(v_{2}(t)\right)= \begin{cases}1.2, & \left|v_{2}(t)\right|<0 \\
1.5, & \left|v_{2}(t)\right| \geq 0\end{cases} \\
& w_{11}\left(v_{1}(t)\right)= \begin{cases}-1.1, & \left|v_{1}(t)\right|<0, \\
-0.8, & \left|v_{1}(t)\right| \geq 0\end{cases}
\end{aligned}
$$

$$
\begin{aligned}
& w_{12}\left(v_{1}(t)\right)= \begin{cases}1.3, & \left|v_{1}(t)\right|<0, \\
-2, & \left|v_{1}(t)\right| \geq 0,\end{cases} \\
& w_{21}\left(v_{2}(t)\right)= \begin{cases}0.4, & \left|v_{2}(t)\right|<0, \\
0.6, & \left|v_{2}(t)\right| \geq 0,\end{cases} \\
& w_{22}\left(v_{2}(t)\right)= \begin{cases}1, & \left|v_{2}(t)\right|<0, \\
-0.5, & \left|v_{2}(t)\right| \geq 0 .\end{cases}
\end{aligned}
$$

It is obvious that $1 \leq a_{i}\left(v_{i}(t)\right) \leq 2, \quad b_{1}^{\prime}(\cdot)=b_{2}^{\prime}(\cdot)=1$, $\left|f_{i}\left(u_{i}\right)-f_{i}\left(v_{i}\right)\right| \leq\left|u_{i}-v_{i}\right|, \quad\left|g_{i}\left(u_{i}\right)-g_{i}\left(v_{i}\right)\right| \leq 2\left|u_{i}-v_{i}\right|, \quad \mid f_{i}$ $\left(u_{i}\right) \mid \leq 1$ and $\left|g_{i}\left(u_{i}\right)\right| \leq 2, \lambda_{i}=\delta_{i}=0$, for any $u_{i}, v_{i} \in \mathbb{R}$, $i=1,2$. Thus, it is easy to obtain that the system (69) satisfies Assumptions 1-5. Taking initial values $v_{1}(t)=-2.5$ and $v_{2}(t)=3$ for $t \in[-1,0]$, the dynamical behavior of system (69) without any controller can be shown in the case of Figure 1(a).

Using the discontinuous state feedback controller (49), we take $p_{i}=q_{i}=8, r_{i}=10$, and $p=2, i=1,2$. By simple computation, we can get Assumption 6 hold and $\omega_{1}=6$, $\omega_{2}=1.2$. Thus, all the conditions in Theorem 2 are satisfied. Therefore, the considered discontinuous system (69) can be stabilized in finite time by using the discontinuous state feedback controller (49). We choose the initial values as $v_{1}(t)=-2.5$ and $v_{2}(t)=3$, for $t \in[-1,0]$. The case of Figure 1(b) shows the dynamical behavior of system (69) with the controller (49). The numerical simulations illustrate the correctness of theoretical results in Theorem 2 . 
Example 2. Consider the following 3-D delayed memristive Cohen-Grossberg neural networks:

$$
\begin{aligned}
\dot{v}_{i}(t)= & -a_{i}\left(v_{i}(t)\right)\left[b_{i}\left(v_{i}(t)\right)-\sum_{j=1}^{3} c_{i j}\left(v_{i}(t)\right) f_{j}\left(v_{j}(t)\right)\right. \\
& \left.-\sum_{j=1}^{3} w_{i j}\left(v_{i}(t)\right) g_{j}\left(v_{j}(t-\tau(t))\right)-I_{i}\right],
\end{aligned}
$$

where

$$
\begin{aligned}
& a_{i}\left(v_{i}(t)\right)=0.85+0.1 \tanh \left(v_{i}(t)\right) \text {, } \\
& f_{i}(\tilde{\theta})=\tanh (\tilde{\theta}) \\
& g_{i}(\tilde{\theta})=3 \tanh (\tilde{\theta}), \\
& \tau(t)=1, \\
& I_{i}=0 \text {, } \\
& \tilde{\theta} \in \mathbb{R}, \\
& i=1,2,3 \text {, } \\
& b_{1}\left(v_{1}(t)\right)=v_{1}(t) \\
& b_{2}\left(v_{2}(t)\right)=v_{2}(t) \text {, } \\
& b_{3}\left(v_{3}(t)\right)=v_{3}(t) \\
& c_{11}\left(v_{1}(t)\right)= \begin{cases}0.5, & \left|v_{1}(t)\right|<0 \\
1, & \left|v_{1}(t)\right| \geq 0\end{cases} \\
& c_{12}\left(v_{1}(t)\right)= \begin{cases}-0.3, & \left|v_{1}(t)\right|<0 \\
-0.1, & \left|v_{1}(t)\right| \geq 0\end{cases} \\
& c_{21}\left(v_{2}(t)\right)= \begin{cases}1, & \left|v_{2}(t)\right|<0, \\
-1, & \left|v_{2}(t)\right| \geq 0\end{cases} \\
& c_{33}\left(v_{3}(t)\right)= \begin{cases}-0.6, & \left|v_{3}(t)\right|<0, \\
-0.2, & \left|v_{3}(t)\right| \geq 0\end{cases} \\
& w_{11}\left(v_{1}(t)\right)= \begin{cases}-1, & \left|v_{1}(t)\right|<0 \\
-0.5, & \left|v_{1}(t)\right| \geq 0\end{cases} \\
& w_{12}\left(v_{1}(t)\right)= \begin{cases}0.8, & \left|v_{1}(t)\right|<0 \\
-1, & \left|v_{1}(t)\right| \geq 0\end{cases} \\
& w_{21}\left(v_{2}(t)\right)= \begin{cases}0.1, & \left|v_{2}(t)\right|<0 \\
1, & \left|v_{2}(t)\right| \geq 0\end{cases}
\end{aligned}
$$

$$
\begin{gathered}
w_{22}\left(v_{2}(t)\right)= \begin{cases}0.5, & \left|v_{2}(t)\right|<0, \\
-0.8, & \left|v_{2}(t)\right| \geq 0,\end{cases} \\
w_{32}\left(v_{3}(t)\right)= \begin{cases}0.3, & \left|v_{3}(t)\right|<0, \\
-0.6, & \left|v_{3}(t)\right| \geq 0,\end{cases} \\
w_{33}\left(v_{3}(t)\right)= \begin{cases}1, & \left|v_{3}(t)\right|<0, \\
-0.6, & \left|v_{3}(t)\right| \geq 0,\end{cases} \\
c_{13}\left(v_{1}(t)\right)=c_{22}\left(v_{2}(t)\right)=c_{23}\left(v_{2}(t)\right)=c_{31}\left(v_{3}(t)\right)=0,
\end{gathered}
$$

It is straightforward to obtain that

$$
\begin{gathered}
0.75 \leq a_{i}\left(v_{i}(t)\right) \leq 0.95, \\
\left|f_{i}\left(u_{i}\right)-f_{i}\left(v_{i}\right)\right| \leq\left|u_{i}-v_{i}\right|, \\
\left|g_{i}\left(u_{i}\right)-g_{i}\left(v_{i}\right)\right| \leq 3\left|u_{i}-v_{i}\right|, \\
\left|f_{i}\left(u_{i}\right)\right| \leq 1, \\
\left|g_{i}\left(u_{i}\right)\right| \leq 3, \\
\lambda_{i}=\delta_{i}=0, \\
b_{1}^{\prime}(\cdot)=b_{2}^{\prime}(\cdot)=\mathrm{b}_{3}^{\prime}(\cdot)=1, \\
u_{i}, v_{i} \in \mathbb{R}, i=1,2,3 .
\end{gathered}
$$

Thus, it is easy to obtain that Assumptions 1-5 and 7 are satisfied. By taking initial values $v_{1}(t)=1, v_{2}(t)=2$, and $v_{3}(t)=-2$ for $t \in[-1,0]$, the case of Figure 2(a) shows the dynamical behavior of system (71) without any controllers.

Using the discontinuous state feedback controller without time-varying delay (62), we take $s_{i}=20$ and $\pi_{i}=10, i=$ $1,2,3$. By simple computation, we can get $\widehat{\omega}>0$ and $\omega^{*}>0$. Thus, all the conditions in Theorem 3 are satisfied. Therefore, the finite-time stability of the discontinuous system (71) with the discontinuous controller (62) can be realized. We choose the initial values as $v_{1}(t)=1, v_{2}(t)=2$, and $v_{3}(t)=-2$ for $t \in[-1,0]$. The case of Figure 2(b) shows the trajectories of the discontinuous system (71) with the discontinuous controller (62). The numerical simulations indicate our theoretical results in Theorem 3 are valid.

\section{Conclusion}

In this paper, the FTS of memristive Cohen-Grossberg neural networks with time-varying delay has been discussed. Based on the novel Kakutani's fixed point theorem of set-valued maps, we have obtained the existence theorem of equilibrium point without assuming the boundedness of the activation functions. Due to the existence of memristor, amplification function, and time-varying delay, the FTS control of memristive Cohen-Grossberg neural networks with time-varying delay is not an easy work. Thus, we have considered two different kinds of discontinuous state feedback controllers whether including time-varying delay and two different analysis methods whether using finite-time stability theory. 


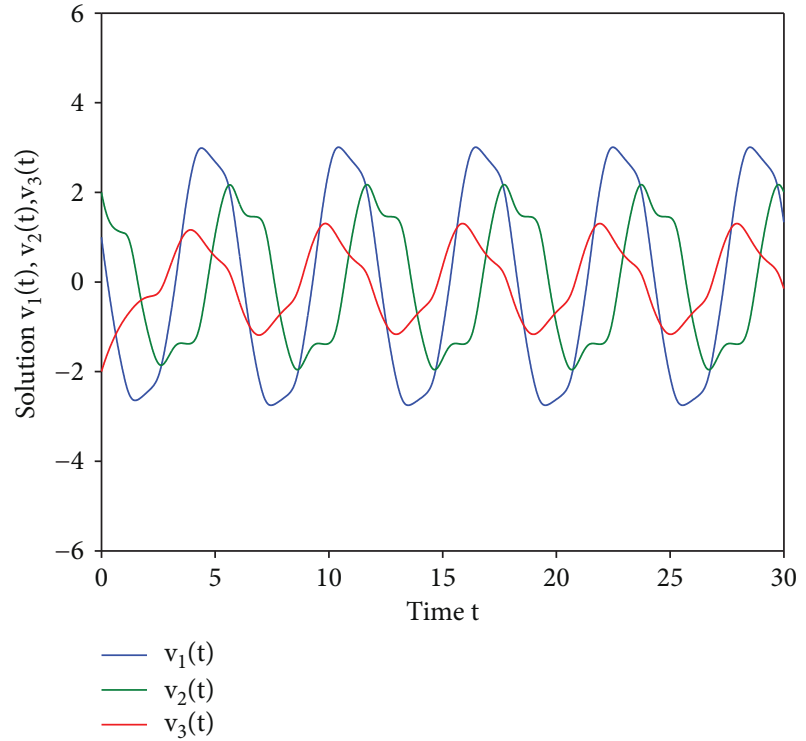

(a)

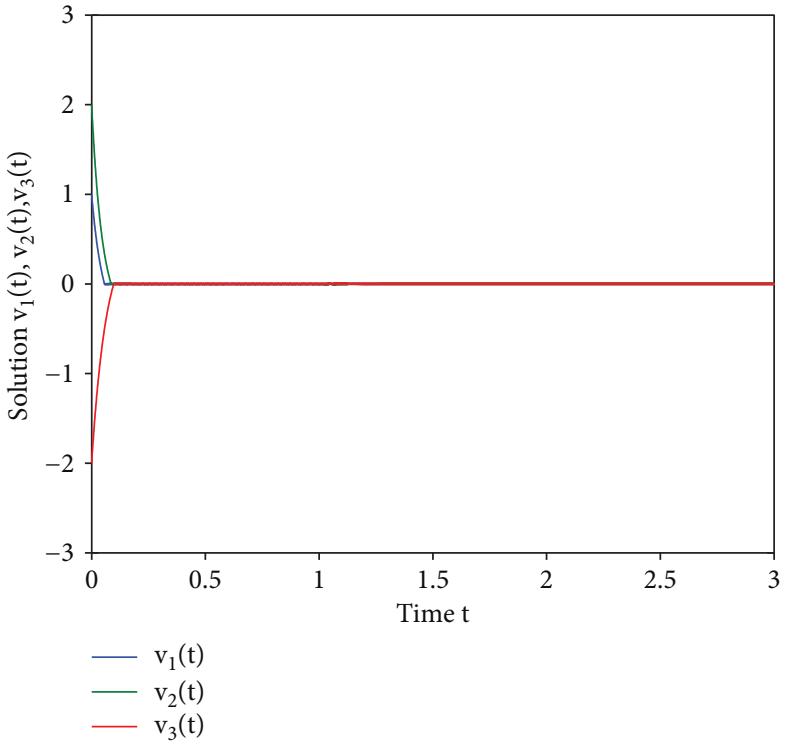

(b)

Figure 2: (a) The trajectories of state variables $v_{1}(t), v_{2}(t)$, and $v_{3}(t)$ in (71) without any controllers. (b) The trajectories of state variables $v_{1}(t), v_{2}(t)$, and $v_{3}(t)$ in (71) with the discontinuous state feedback controller (62).

Under the extended Filippov framework and some inequality techniques, several sufficient conditions for guaranteeing the FTS have been obtained. In addition, the settling time for FTS are also proposed. Finally, two numerical examples have been used to illustrate the validity of theoretical results. On the other hand, it is a very effective method to investigate the FTS of the discontinuous system (1) by using the equivalent transformation system (8). The approaches in this paper can also be extended to study the fixed-time stabilization and fixed-time synchronization of other types of Cohen-Grossberg neural networks. Besides, it is well known that the factor of impulse has an important effect on the neural networks. In the future research, we hope to study the fixed-time stabilization and fixed-time synchronization problem of other more complex Cohen-Grossberg neural networks, such as concerning the factor of impulse or mixed delays [36-40]. Meanwhile, how to design more simple and effective controllers is also our future research topic.

\section{Data Availability}

In the numerical examples, we have verified that all the conditions in Theorem 2 and Theorem 3 are hold. Then, the correctness of theoretical results is illustrated by using MATLAB programming. If the data used in MATLAB programming does not satisfy all the conditions in the two theorems, the numerical simulations are incorrect and cannot verify the correctness of theoretical results. Or available from the corresponding author upon request.

\section{Conflicts of Interest}

The authors declare that they have no conflicts of interest.

\section{Acknowledgments}

This research was supported by the National Natural Science Foundation of China (Grant No. 71171077) and China Hunan Provincial Science and Technology Department (2015JC3050).

\section{References}

[1] L. O. Chua, "Memristor-the missing circuit element," IEEE Transactions on Circuit Theory, vol. 18, no. 5, pp. 507519, 1971.

[2] D. B. Strukov, G. S. Snider, D. R. Stewart, and R. S. Williams, "The missing memristor found," Nature, vol. 453, no. 7191, pp. 80-83, 2008.

[3] Y. V. Pershin and M. Di Ventra, "Experimental demonstration of associative memory with memristive neural networks," Neural Networks, vol. 23, no. 7, pp. 881-886, 2010.

[4] S. P. Adhikari, C. Yang, H. Kim, and L. O. Chua, "Memristor bridge synapse-based neural network and Its learning," IEEE Transactions on Neural Networks and Learning Systems, vol. 23, no. 9, pp. 1426-1435, 2012.

[5] K. D. Cantley, A. Subramaniam, H. J. Stiegler, R. A. Chapman, and E. M. Vogel, "Hebbian learning in spiking neural networks with nanocrystalline silicon TFTs and memristive synapses," IEEE Transactions on Nanotechnology, vol. 10, no. 5, pp. 1066-1073, 2011.

[6] I. E. Ebong and P. Mazumder, "CMOS and memristor-based neural network design for position detection," Proceedings of the IEEE, vol. 100, no. 6, pp. 2050-2060, 2012.

[7] R. Rakkiyappan, G. Velmurugan, F. A. Rihan, and S. Lakshmanan, "Stability analysis of memristor-based complex-valued recurrent neural networks with time delays," Complexity, vol. 21, no. 4, pp. 14-39, 2016. 
[8] Y. Shi, J. Cao, and G. Chen, "Exponential stability of complexvalued memristor-based neural networks with time-varying delays," Applied Mathematics and Computation, vol. 313, pp. 222-234, 2017.

[9] R. Rakkiyappan, G. Velmurugan, and J. Cao, "Stability analysis of memristor-based fractional-order neural networks with different memductance functions," Cognitive Neurodynamics, vol. 9, no. 2, pp. 145-177, 2015.

[10] Z. Guo, J. Wang, and Z. Yan, "Global exponential synchronization of two memristor-based recurrent neural networks with time delays via static or dynamic coupling," IEEE Transactions on Systems, Man, and Cybernetics: Systems, vol. 45, no. 2, pp. 235-249, 2015.

[11] Z. Guo, S. Yang, and J. Wang, "Global synchronization of memristive neural networks subject to random disturbances via distributed pinning control," Neural Networks, vol. 84, pp. 67-79, 2016.

[12] Z. Guo, S. Gong, S. Wen, and T. Huang, "Event-based synchronization control for memristive neural networks with time-varying delay," IEEE Transactions on Cybernetics, pp. 1-10, 2018.

[13] S. P. Bhat and D. S. Bernstein, "Finite-time stability of homogeneous systems," in Proceedings of the 1997 American Control Conference (Cat. No.97CH36041), pp. 2513-2514, Albuquerque, NM, USA, 1997.

[14] J. Cortés, "Finite-time convergent gradient flows with applications to network consensus," Automatica, vol. 42, no. 11, pp. 1993-2000, 2006.

[15] X. Liu, D. W. C. Ho, J. Cao, and W. Xu, "Discontinuous observers design for finite-time consensus of multiagent systems with external disturbances," IEEE Transactions on Neural Networks and Learning Systems, vol. 28, no. 11, pp. 2826-2830, 2017.

[16] Z. Cai, L. Huang, and L. Zhang, "Finite-time synchronization of master-slave neural networks with time-delays and discontinuous activations," Applied Mathematical Modelling, vol. 47, pp. 208-226, 2017.

[17] M. Zheng, L. Li, H. Peng, J. Xiao, Y. Yang, and H. Zhao, "Finite-time projective synchronization of memristor-based delay fractional-order neural networks," Nonlinear Dynamics, vol. 89, no. 4, pp. 2641-2655, 2017.

[18] X. Liu, D. W. C. Ho, W. Yu, and J. Cao, “A new switching design to finite-time stabilization of nonlinear systems with applications to neural networks," Neural Networks, vol. 57, pp. 94-102, 2014.

[19] X. Liu, J. H. Park, N. Jiang, and J. Cao, "Nonsmooth finite-time stabilization of neural networks with discontinuous activations," Neural Networks, vol. 52, pp. 25-32, 2014.

[20] Z. Cai, L. Huang, M. Zhu, and D. Wang, "Finite-time stabilization control of memristor-based neural networks," Nonlinear Analysis: Hybrid Systems, vol. 20, pp. 37-54, 2016.

[21] L. Wang and Y. Shen, "Finite-time stabilizability and instabilizability of delayed memristive neural networks with nonlinear discontinuous controller," IEEE Transactions on Neural Networks and Learning Systems, vol. 26, no. 11, pp. 2914-2924, 2015.

[22] R. Li and J. Cao, "Finite-time stability analysis for Markovian jump memristive neural networks with partly unknown transition probabilities," IEEE Transactions on Neural Networks and Learning Systems, vol. 28, no. 12, pp. 29242935, 2017.
[23] M. Zheng, L. Li, H. Peng et al., "Finite-time stability and synchronization of memristor-based fractional-order fuzzy cellular neural networks," Communications in Nonlinear Science and Numerical Simulation, vol. 59, pp. 272-291, 2018.

[24] M. A. Cohen and S. Grossberg, “Absolute stability of global pattern formation and parallel memory storage by competitive neural networks," IEEE Transactions on Systems, Man, and Cybernetics, vol. SMC-13, no. 5, pp. 815-826, 1983.

[25] C. Rajivganthi, F. A. Rihan, S. Lakshmanan, and P. Muthukumar, "Finite-time stability analysis for fractionalorder Cohen-Grossberg BAM neural networks with time delays," Neural Computing and Applications, vol. 29, no. 12, pp. 1309-1320, 2018.

[26] M. Liu, H. Jiang, and C. Hu, "Finite-time synchronization of memristor-based Cohen-Grossberg neural networks with time-varying delays," Neurocomputing, vol. 194, pp. 1-9, 2016.

[27] Y. Wan, J. Cao, G. Wen, and W. Yu, "Robust fixed-time synchronization of delayed Cohen-Grossberg neural networks," Neural Networks, vol. 73, pp. 86-94, 2016.

[28] M. Zheng, L. Li, H. Peng, J. Xiao, Y. Yang, and H. Zhao, "Finite-time stability and synchronization for memristorbased fractional-order Cohen-Grossberg neural network," European Physical Journal B, vol. 89, no. 9, p. 204, 2016.

[29] L. Huang, Z. Guo, and J. Wang, Theory and Applications of Differential Equations with Discontinuous Right-Hand Sides, Science Press, Beijing, China, 2011.

[30] Z. Cai, L. Huang, D. Wang, and L. Zhang, "Periodic synchronization in delayed memristive neural networks based on Filippov systems," Journal of the Franklin Institute, vol. 352, no. 10, pp. 4638-4663, 2015.

[31] M. Forti, M. Grazzini, P. Nistri, and L. Pancioni, "Generalized Lyapunov approach for convergence of neural networks with discontinuous or non-Lipschitz activations," Physica D: Nonlinear Phenomena, vol. 214, no. 1, pp. 88-99, 2006.

[32] L. L. Zhang, L. H. Huang, and Z. W. Cai, "Finite-time stabilization control for discontinuous time-delayed networks: new switching design," Neural Networks, vol. 75, pp. 84-96, 2016.

[33] J. Cao, "New results concerning exponential stability and periodic solutions of delayed cellular neural networks," Physics Letters A, vol. 307, no. 2-3, pp. 136-147, 2003.

[34] Z. Cai, X. Pan, L. Huang, and J. Huang, "Finite-time robust synchronization for discontinuous neural networks with mixed-delays and uncertain external perturbations," Neurocomputing, vol. 275, pp. 2624-2634, 2018.

[35] L. Wang, Y. Shen, and G. Zhang, "Finite-time stabilization and adaptive control of memristor-based delayed neural networks," IEEE Transactions on Neural Networks and Learning Systems, vol. 28, no. 11, pp. 2648-2659, 2017.

[36] Z. W. Cai and L. H. Huang, "Finite-time synchronization by switching state-feedback control for discontinuous CohenGrossberg neural networks with mixed delays," International Journal of Machine Learning and Cybernetics, vol. 9, no. 10, pp. 1683-1695, 2018.

[37] X. Liu, D. W. C. Ho, Q. Song, and W. Xu, "Finite/fixedtime pinning synchronization of complex networks with stochastic disturbances," IEEE Transactions on Cybernetics, pp. 1-6, 2018.

[38] X. Liu, D. W. C. Ho, Q. Song, and J. Cao, "Finite-/fixed-time robust stabilization of switched discontinuous systems with disturbances," Nonlinear Dynamics, vol. 90, no. 3, pp. 20572068, 2017. 
[39] X. Li and S. Song, "Stabilization of delay systems: delaydependent impulsive control," IEEE Transactions on Automatic Control, vol. 62, no. 1, pp. 406-411, 2017.

[40] X. Li and J. Wu, "Stability of nonlinear differential systems with state-dependent delayed impulses," Automatica, vol. 64, pp. 63-69, 2016. 


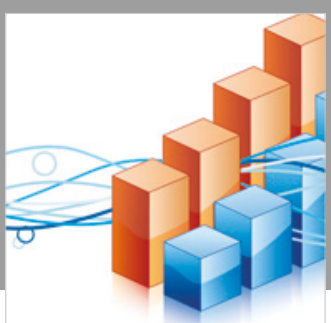

Advances in

Operations Research

\section{-n-m}
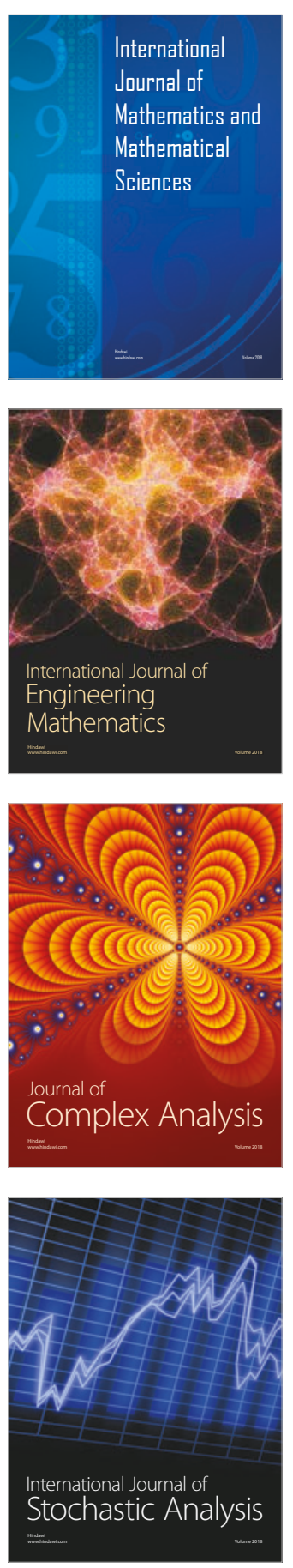
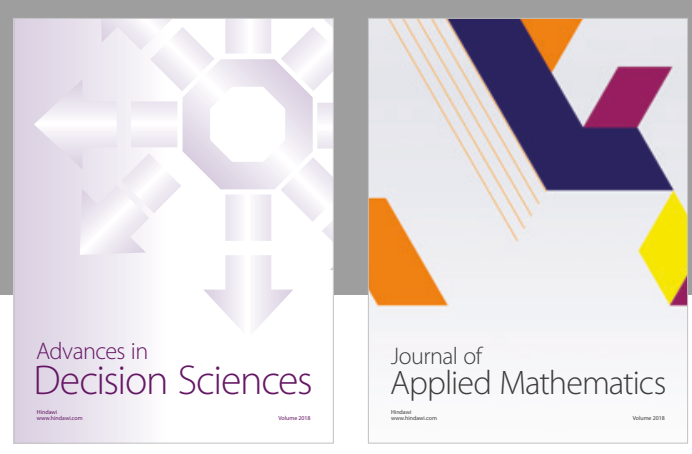

Journal of

Applied Mathematics
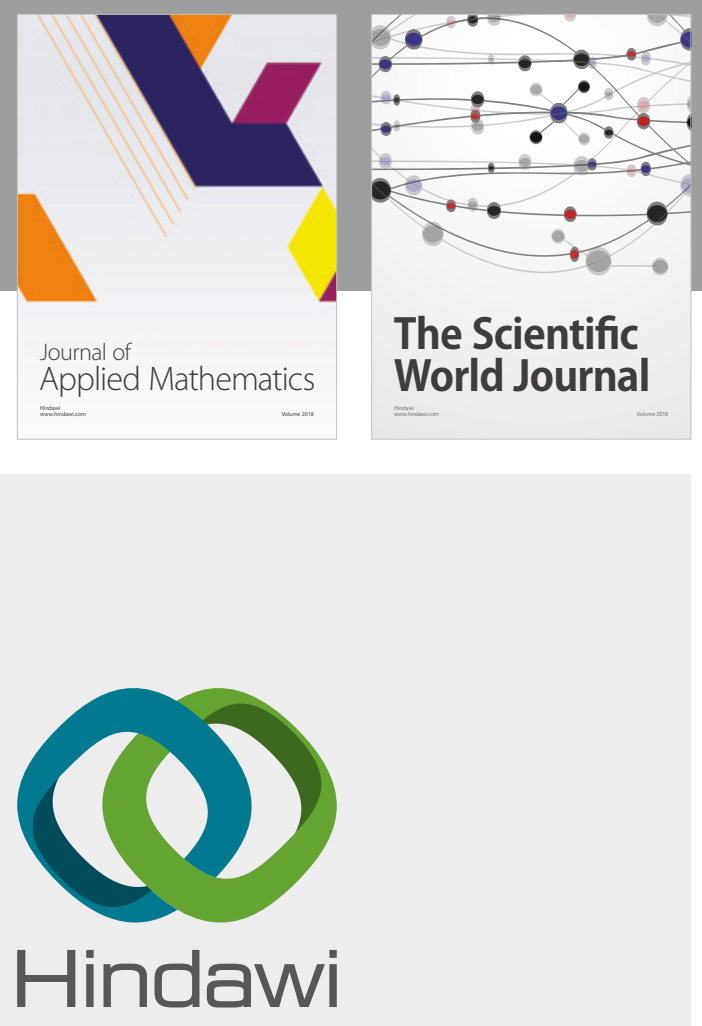

Submit your manuscripts at

www.hindawi.com

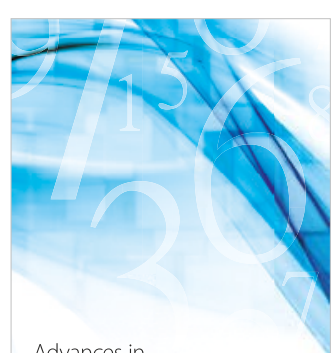

Advances in
Numerical Analysis
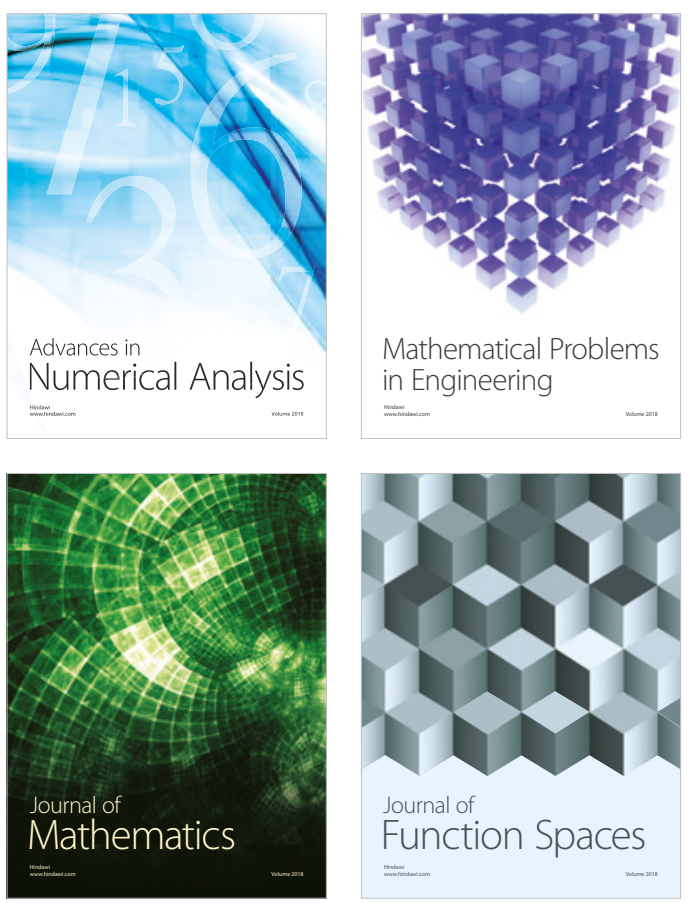

Mathematical Problems in Engineering

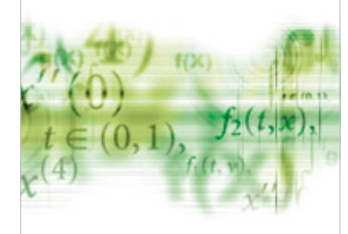

International Journal of

Differential Equations

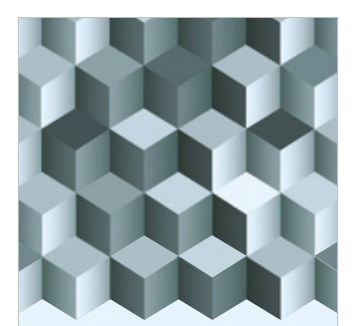

Journal of

Function Spaces
The Scientific

World Journal

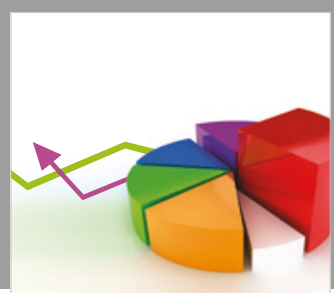

Journal of

Probability and Statistics
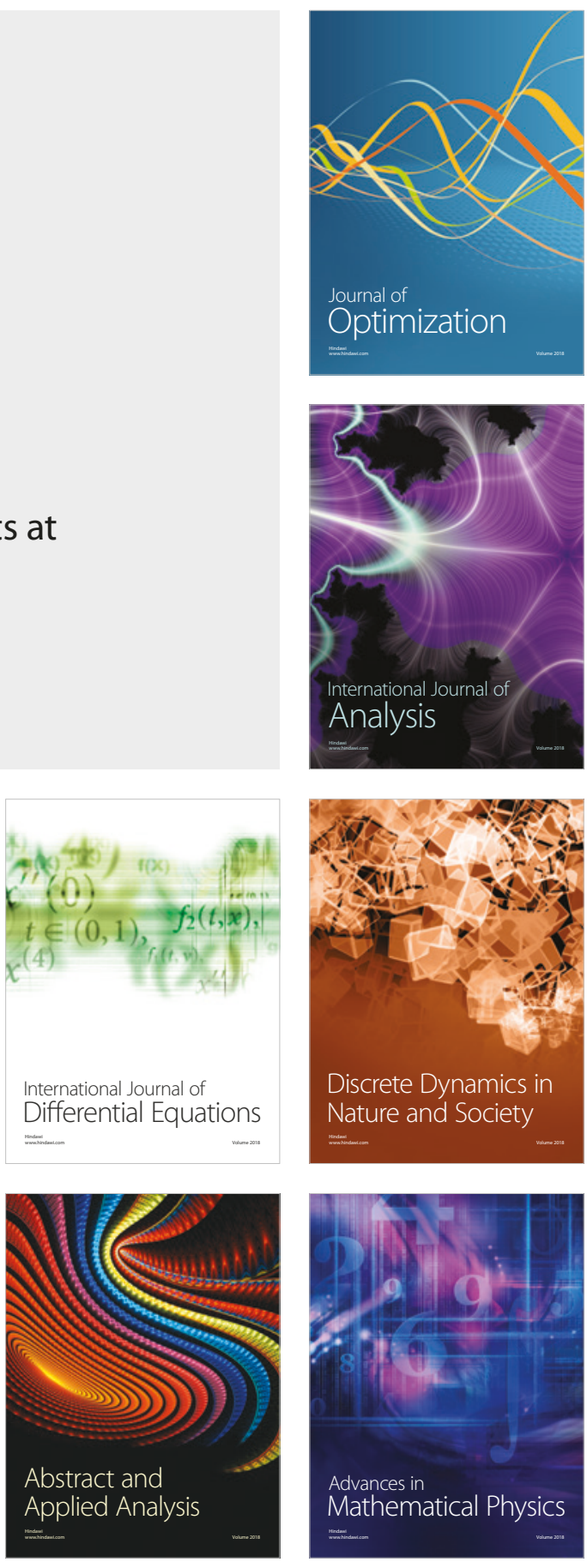